\title{
Sirtuins and their Biological Relevance in Aging and Age- Related Diseases
}

\author{
Lijun Zhao ${ }^{1}$, Jianzhong $\mathrm{Cao}^{2}$, Kexin Hu${ }^{1}$, Xiaodong $\mathrm{He}^{2}$, Dou Yun ${ }^{1}$, Tanjun Tong ${ }^{*}$, Limin Han ${ }^{1^{*}}$ \\ ${ }^{1}$ Peking University Research Center on Aging, Department of Biochemistry and Molecular Biology, School of \\ Basic Medical Sciences, Peking University Health Science Center, Beijing Key Laboratory of Protein \\ Posttranslational Modifications and Cell Function, Beijing, China \\ ${ }^{2}$ Department of General Surgery, Peking Union Medical College Hospital, Chinese Academy of Medical Sciences \\ \& Peking Union Medical College, Beijing, China.
}

[Received July 29, 2019; Revised August 19, 2019; Accepted August 20, 2019]

\begin{abstract}
Sirtuins, initially described as histone deacetylases and gene silencers in yeast, are now known to have many more functions and to be much more abundant in living organisms. The increasing evidence of sirtuins in the field of ageing and age-related diseases indicates that they may provide novel targets for treating diseases associated with aging and perhaps extend human lifespan. Here, we summarize some of the recent discoveries in sirtuin biology that clearly implicate the functions of sirtuins in the regulation of aging and age-related diseases. Furthermore, human sirtuins are considered promising therapeutic targets for anti-aging and ageing-related diseases and have attracted interest in scientific communities to develop small molecule activators or drugs to ameliorate a wide range of ageing disorders. In this review, we also summarize the discovery and development status of sirtuin-targeted drug and further discuss the potential medical strategies of sirtuins in delaying aging and treating age-related diseases.
\end{abstract}

Key words: sirtuins, aging, age-related diseases, cancer

In 1979, the discovery of mating-type regulator 1 (MAR1) in Saccharomyces cerevisiae was reported [1]. Lack of this protein resulted in the inhibition of silencing of HM loci, which control mating type and sterility in yeast. Three more proteins with similar functions were discovered later in 1979, and the nomenclature was unified, thus creating a family of silent information regulator proteins, Sirs [2]. Emerging interest in sirtuins occurred in 1999 when it was reported that Sir2 overexpression could extend yeast lifespans by as much as $70 \%$ [3]. Further research revealed that sirtuins overexpression also leads to lifespan extension in other model organisms, such as Caenorhabditis elegans and Drosophila melanogaster.
Shortly thereafter, it was shown that sirtuins appear to be conserved from yeast to mammals, however the complexity of their function increases with the complexity of the organism [4]. In yeast, in addition to the chief representative, Sir2, there are four more homologous proteins [2], and the positive effect of sirtuins activity can be attributed to the increase in genomic stability. In mammals there are seven enzymes belonging to the sirtuin family, sirt1-7. Phylogenetic analysis of 60 core domains from different eukaryotes and prokaryotes places the mammalian sirtuins into four different classes (I-IV). Sirt1, sirt2 and sirt3 are known as Class I sirtuins, which groups all yeast sirtuins and also at least one of the sir2related proteins in most eukaryotes. Class I is divided in

*Correspondence should be addressed to: Dr. Limin Han (liminhan@bjimu.edu.cn) and Dr. Tanjun Tong (ttj@bjmu.edu.cn), Department of Biochemistry \& Molecular Biology, Peking University Health Science Center, Beijing 100191, China.

Copyright: ( 2019 Zhao L et al. This is an open-access article distributed under the terms of the Creative Commons Attribution License, which permits unrestricted use, distribution, and reproduction in any medium, provided the original author and source are credited. 
three sub-classes: a, b and c. Sirtl belongs to Class Ia which also includes Sir2 and Hst 1 from S. cerevisiae, $C$. elegans Sir-2.1 and D. melanogaster D.mel1. Sirt2 and sirt3 reside in Class $\mathrm{Ib}$, together with yeast $H s t 2$, fly D.mel2 and other fungi and protozoa sirtuins. Sirt4 is part of Class II, which also includes sirtuins from bacteria, insects, nematodes, mould fungus and protozoans. Sirt 5 is the mammalian member of Class III sirtuins, distributed widely in all prokaryotes either bacteria or archaea. Finally, Class IV contains sirt6 and sirt7 in two different sub-classes IVa and IVb respectively; and unlike Class III, sirtuins of this class are not present in prokaryotes, but are broadly distributed in metazoans, plants and vertebrates [5].

In addition, mammalian sirtuins also differ in their sub-cellular localization, and some sirtuins can relocalize depending on the cell or tissue type, the developmental stage, metabolic status, and certain stress conditions. Sirt1 is localized to the nucleus [6], but it shuttles to the cytoplasm when required to act on cytoplasmic targets, such as during inhibition of insulin signaling [7]. In contrast, sirt2 is cytoplasmic. It deacetylates tubulin microtubules [8] and transcription factors those shuttle from the cytoplasm to the nucleus [9]. Sirt3, sirt4 and sirt5 are active in the mitochondria [10] by participating in the regulation of Adenosine Triphosphate (ATP) synthesis, metabolism, apoptosis and intracellular signaling [11]. Among them, sirt3 may be moved between the nucleus and mitochondria under cellular stress [2]. Sirt6 is a nuclear protein, although it is also present in the endoplasmic reticulum, where it deacetylates TNF- $\alpha$ [12]. Sirt7 is a nuclear protein that is mostly expressed in the nucleolar regions [13].

Table 1. The location and enzymatic catalytic activity of sirtuins.

\begin{tabular}{|llll|}
\hline Sirtuin & Class & localivation & Enryymatic activity \\
\hline Sirt1 & I & Nuclear/Cytosolic & Deacetylase, Deacylase \\
\hline Sirt2 & I & Nuclear/Cytosolic & Deacetylase, Deacylase \\
\hline Sirt3 & I & Mitochondrial/ Nuclear/Cytosolic & Deacetylase, Decrotonylase \\
\hline Sirt4 & II & Mitochondrial & Deacetylase, ADP-ribosyltransferase, Lipoamidase, Deacylase \\
\hline Sirt5 & III & Mitochondrial/ Nuclear/Cytosolic & Deacetylase, Desuccinylase, Demalonylase, Deglutarylase \\
\hline Sirt6 & IV & Nuclear/Cytosolic & Deacetylase, Demyristoylase, ADP-ribosyltransferase, Deacylase \\
\hline Sirt7 & IV & Nucleolar/nuclear & Deacetylase, Desuccinylase \\
\hline
\end{tabular}

\section{Overview of sirtuins functions}

Sirtuins belong to the class III histone deacetylases (HDACs) [14].The sirtuin family shares a highly conserved catalytic domain, and exerts $\mathrm{NAD}^{+}$-dependent protein deacylase and/or ADP ribosyltransferase activities $[15,16]$. However, as shown in Table $1 \&$ Table 2, the sirtuin family members differ from one another with respect to catalytic activities, subcellular localization, protein targets, and biological functions [17].

Studies indicate that, from yeast to humans, sirtuins contain a highly conserved catalytic core domain formed by 275 amino acids, and N,C-terminal extensions which is variable in length and sequence, and can affect the binding with interacting partners, mediate interactions with other sirtuin forms, and direct cellular localization. In addition to their well-studied roles as lysine deacetylases, certain sirtuins can also remove other acyl modifications from lysine residues, including propionyl, butyryl, malonyl, succinyl and the lengthy fatty-acid derived myristoyl and palmitoyl groups [18-22]. In addittion, sirtuins possess $\mathrm{NAD}^{+}$-dependent deacetylase, deacylase, desuccinylase, demalonylase, deglutarylase, ADP-ribosyltransferase activities, etc. and regulate many processes in vivo, including metabolism, DNA repair, metastasis, apoptosis, translation, promoting longevity and protecting against cancer via altering substrate activity, localization, stability and protein-protein interactions [23].

Sirt1 is the closest to yeast Sir2 in terms of sequence and enzymatic activity and is also the most extensively studied mammalian sirtuin at present. Sirtl deacetylates a diverse array of cellular proteins, including histones, transcription factors, DNA repair proteins, autophagy factors, and others, like FOXO3a, PPAR $\alpha$, PGAM-1, SREBP1, FXR, PGC-1 $\alpha, \mathrm{NF}-\kappa \mathrm{B}$, etc [24] to modulate metabolism, stress responses, and other cellular processes [25]. In vitro, sirtl possesses deacylase activity, although the functional significance of this activity in vivo remains unclear [26].

Sirt2 mainly functions in mitosis. Sirt2 regulates mitotic progression by controlling the activity of the anaphase-promoting complex/cyclosome. When DNA damage emerges, sirt 2 may halt cell division, effectively guarding the cell against erroneous replication. Sirt2 also plays an important role in controlling the cell cycle. In fact, an increase in sirt 2 activity significantly delays cell cycle progression [27]. In addition, the overall effect of sirt2 upregulation on carbohydrate and lipid metabolism is similar to that of sirtl, promoting gluconeogenesis 
through deacetylation of phosphoenolpyruvate carboxykinase (PEPCK) [28] and inhibiting adipocyte differentiation through deacetylation of FoxO1 [9, 29]. Furthermore, sirt2 also has anti-inflammatory effects [30].

Sirt3 is a mitochondrial enzyme, and it deacetylates and activates mitochondrial enzymes to regulate diverse mitochondrial functions, such as ATP production, reactive oxygen species (ROS) management, $\beta$-oxidation, ketogenesis, and cell death [31]. The metabolic actions of sirt3 on carbohydrate and lipid metabolism are similar to those of sirtl (e.g., stimulation of gluconeogenesis, inhibition of lipogenesis, activation of fatty acid oxidation, and some neuroprotective actions) [32]. Furthermore, sirt3 has also been related to adaptive thermogenesis because of its regulation in both white and brown adipose tissue by caloric restriction (CR) and cold exposure [33].

Unlike the other sirtuins, sirt4 is a mitochondrial sirtuin lacking in vitro deacetylase activity [34]. Biologically, sirt4 functions in many important processes, particularly in glutamine and fatty acid metabolism [35]. Sirt4 is also thought to regulate ATP homeostasis. Sirt4 improves the efficacy of ATP synthesis by inhibiting the oxidative phosphorylation uncoupler ANT2 [36].

Table 2. The substrates/targets and functions of sirtuins.

\begin{tabular}{|c|c|c|c|c|}
\hline \multicolumn{4}{|c|}{ Substrates/targets } & \multirow[b]{2}{*}{ Function } \\
\hline & Modification & Activation & Inhiibition & \\
\hline SIRT1 & $\begin{array}{l}\text { H3К9ac, H3К26аc, } \\
\text { H3K16ac, H1K26, } \\
\text { H1K9, H3K56, } \\
\text { H3K14, H4K16, } \alpha- \\
\text { tubulin, p53 }\end{array}$ & $\begin{array}{l}\text { Suv39h1, N-Myc, ER, Sirt6, } \\
\text { ADAM-10, LKB1, AMPK, } \\
\text { NBS1, XPA, MnSOD, } \\
\text { WRN, Ku70, FOXO1/3, } \\
\text { PGC-1a, PPAR } \alpha, \text { FXR }\end{array}$ & $\begin{array}{l}\text { NF-KB, p300, } \\
\text { p } 66^{\text {shc }}, \text { mTOR, HIF- } \\
\text { 1a, TNF-1a, Histone } \\
\text { acctylation, SREBP- } \\
\text { 1c }\end{array}$ & $\begin{array}{l}\text { Glucose metabolism, fatty-acid and } \\
\text { cholesterol metabolism, differentiation, } \\
\text { insulin secretion, and neuroprotection, } \\
\text { stress responses, DNA repair, vascular } \\
\text { protection and other cellular processes }\end{array}$ \\
\hline SIRT2 & $\begin{array}{l}\alpha \text {-tubulin, } \\
\text { H3K56ac, } \\
\text { H4K16ac, }\end{array}$ & $\begin{array}{l}\text { FOXO, c-Myc, G6PD, } \\
\text { PEPCK }\end{array}$ & NF-KB, p53, FoxO1 & $\begin{array}{l}\text { Cell-cycle control, carbohydrate and lipid } \\
\text { metabolism, tubulin and transcription } \\
\text { factors deacetylation and anti- } \\
\text { inflammatory }\end{array}$ \\
\hline SIRT3 & $\begin{array}{l}\text { H3K9, H4K16, } \\
\text { H3K56ac, } \\
\text { H4K14ac, }\end{array}$ & $\begin{array}{l}\mathrm{Ku} 70, \mathrm{Mn}-\mathrm{SOD}, \mathrm{FOXO} 3 \mathrm{a}, \\
\mathrm{DH} 2, \mathrm{FAO}, \mathrm{GDH}, \\
\text { complexI/III, IDH2 }\end{array}$ & $\begin{array}{l}\text { p53, HIF-1a, Ros, } \\
\text { lipogcncasis }\end{array}$ & $\begin{array}{l}\text { regulation of mitochondrial enzymes } \\
\text { deacetylation, ATP production, reactive } \\
\text { oxygen species (ROS) management, b- } \\
\text { oxidation, ketogenesis, cell death, and } \\
\text { carbohydrate and lipid metabolism }\end{array}$ \\
\hline SIRT4 & & & $\begin{array}{l}\text { GDH, AMPK, ROS, } \\
\text { PDH }\end{array}$ & $\begin{array}{l}\text { Insulin secretion, glutamine and fatty acid } \\
\text { metabolism and regulate the ATP } \\
\text { homeostasis }\end{array}$ \\
\hline SIRT5 & CPS1 & SOD1 & GLS & $\begin{array}{l}\text { Urea cycle, regulation of ATP synthesis, } \\
\text { metabolism, apoptosis and intracellular } \\
\text { signaling, regulation of ammonia } \\
\text { detoxification, fatty acid oxidation }\end{array}$ \\
\hline SIRT6 & $\begin{array}{l}\text { H2BK12, H3K9ас } \\
\text { H3K56ac, WRN }\end{array}$ & $\begin{array}{l}\text { FOXO, PARP1, CtIP, P53, } \\
\text { DNA-PKcs, CCNDBP1 }\end{array}$ & $\begin{array}{l}\text { NF-KB, RELA, } \\
\text { TNF-a, IGF-1, HIF- } \\
\text { 1a, Myc, c-Jun, } \\
\text { PGC-1a, GCN5 }\end{array}$ & $\begin{array}{l}\text { Telomeres and telomeric functions, DNA } \\
\text { repair, metabolic homeostasis, } \\
\text { inflammation, stress responses, and } \\
\text { genomic stability }\end{array}$ \\
\hline SIRT7 & $\begin{array}{l}\mathrm{H} 2 \mathrm{~A}, \mathrm{H} 2 \mathrm{~B}, \mathrm{H} 3 \\
\text { (H3K18) }\end{array}$ & FOXO & $\begin{array}{l}\text { RNA-POLY-merase, } \\
\text { HIF-1a/2a }\end{array}$ & $\begin{array}{l}\text { regulates the transcription of rDNA and } \\
\text { mediate histone desuccinylation }\end{array}$ \\
\hline
\end{tabular}

Sirt5 is a mitochondrial enzyme [20]. It is now known that newly discovered PTMs removed by sirt5 can regulate the activity of enzymes affecting the redox status of cells and energy utilization, but we have just started to learn about the exact influence of sirt5 on these pathways. In addition to the deacylase activities of sirt5, recent studies have suggested that sirt5 can mediate protein desuccinylation, demalonylation, and deglutarylation [21, 37, 38].

Sirt6 deacetylates specific cellular targets: H3K9Ac and H3K56Ac, the DNA repair factor CtIP, and the acetyltransferase GCN5 [39]. Recent studies have shown that sirt6 also has a deacylase activity [19]and interacts physically with some non-histone proteins - not only through deacylation, but also through direct physical interaction (PIA), inhibition of their binding at the target gene promoters (IATGP) and destabilization of their binding at the target gene promoters (DATGP)[40]. Through these functions, sirt6 plays essential roles in metabolic homeostasis, inflammation, stress responses, and genomic stability [41]. 
Sirt7 is the only sirtuin localized to the nucleolus and is a component of the RNA polymerase I (Pol I) transcriptional machinery. By interacting with RNA Pol I and histones, sirt7 regulates the transcription of rDNA in mammalian cells [42]. In addition, sirt7 can mediate histone desuccinylation [43].

\section{Sirtuins and aging}

Ageing is a conserved phenomenon across all species and imposes an ever-increasing risk of dysfunction and death in older organisms. Growing evidences have shown that sirtuins are essential factors those delay cellular senescence and extends the organismal lifespan through the regulation of diverse cellular processes. Therefore, in the review, we summarize the evidences and controversies regarding the roles of different sirtuins on aging and lifespan extension, and systematically elucidate the functions and pathways of sirtuins on aging and lifespan extension.

The link between sirtuins and longevity was first established 20 years ago in yeast, in which the complex of Sir2/3/4 extended the replicative lifespan of S. cerevisiae $[44,45]$.Research interests increased after a report showed that extra copies of Sir2, a member of sirtuins in budding yeast Saccharomyces cerevisiae, extended the lifespan by $30 \%$ by preventing the formation of extrachromosomal DNA circles [3]. Subsequently, more and more research shows that sirtuins can regulate longevity in numerous lower organisms, especially yeast Sir2 and its homologues, which extend the lifespan of budding yeast $S$. cereviseasae, worms $C$. elegans, fruit flies D. melanogaster, and mice [46-48]. So far, The prolongevity effect of sir2 has been confirmed in higher organisms, while the mechanisms of exerting prolongevity effects are different from that in yeast, including changes in mitochondrial function and biogenesis, suppression of inflammation, and regulation of genomic stability [49].

Though several reports have challenged this theory, sirtuins have long been recognized as regulators of ageing, and overexpression of some sirtuins has been shown to extend lifespan in several organisms. The suppression of cellular senescence by sirtuin is mainly mediated through delaying the age-related telomere attrition, sustaining genome integrity and promoting DNA damage repair [50]. According to reports, sirtl deacetylates histones $\mathrm{H} 3$, $\mathrm{H} 4$ and $\mathrm{H} 1$ and more than 50 non-histone proteins, including DNMT1, transcription factors and DNA repair proteins [2]. Sirtl and sirt6 were shown to be recruited to the damaged sites and promote DNA repair through deacetylating the repair proteins such as poly (ADPribose) polymerase (PARP)-1, Ku70, NBS, and Werner (WRN) helicase [12, 51-53]. In mammals, sirtuin upregulation can work in a context-, tissue-, and particular sirtuin-dependent manner [54], and not all laboratories have managed to repeat the initial life span extending effect of sirtuins upregulation $[55,56]$.In addition, sirtuins are found to especially interact with all the major conserved longevity pathways, such as AMP-activated protein kinase (AMPK), insulin/IGF-1 signaling (IIS), target of rapamycin (TOR), and forkhead box O (FOXO). Of these, FOXO transcription factor is the most fascinating target of sirtuin. In C. elegans, the extension of lifespan by elevation of sir-2.1 was shown to be dependent on daf-16, the homologue of FOXO in worms [57-59]. Considering that FOXO is a major component in the IIS cascade to promote lifespan extension and stress resistance, several evidences have reported the association of the IIS pathway with the prolongevity effect of sirtuin. In C. elegans, the deletion of sir- 2.1 had no effect on the lifespan of a long-living daf- 2 mutants [60]. In mammals, the relationship of IIS and sirtuin has also been well investigated. Sirtl is reported to play a crucial role in metabolic homeostasis and IIS [61, 62]. AMPK signaling belongs to the protein kinase family and restores cellular energy levels. Increased AMPK activity is known to extend the lifespan of some model organisms. The mutation of AMPK (aak-2) in C. elegans abrogated the lifespan extension by sir-2.1 expression [63], indicating that AMPK also contributes to the sirtuininduced lifespan extension. Sirt1 activates AMPK through the direct deacetylation of LKB1, a regulator of AMPK [64]. In addition, AMPK contributes to the prolongevity effect of IIS, suggesting that these longevity pathways intricately cross-talk with each other. Apart from these, several other molecules are also reported to mediate lifespan extension by sirtuin overexpression, including 14-3-3, kat-1, hcf-1, and cts- 1 in C. elegans. In addition, a study of mutant screening reported that lossof-function mutations of ketoacyl thiolase (kat-1) resulted in premature aging and fully suppressed the lifespan extension exerted by overexpression of sir-2.1 [65]. Also, host cell factor-1 (hcf-1), a nuclear co-repressor of FOXO, was shown to act downstream of sir-2.1 to modulate the lifespan in C. elegant [66]. Furthermore, mitochondrial regulators such as cts- 1 and fzo- 1 , and the mitochondrial unfolded protein response (UPRmt) gene hsp-6, were reported to be increased by sir- 2.1 overexpression, and the knock-down of UPRmt regulator ubl-5 using RNAi almost completely suppressed the lifespan extension by sir-2.1 overexpression [67]. A more detailed description of the role about different sirtuins on aging and lifespan extension, and the signaling pathways are listed in Table 3. 
Table 3. Functions and signaling pathway of sirtuins in aging.

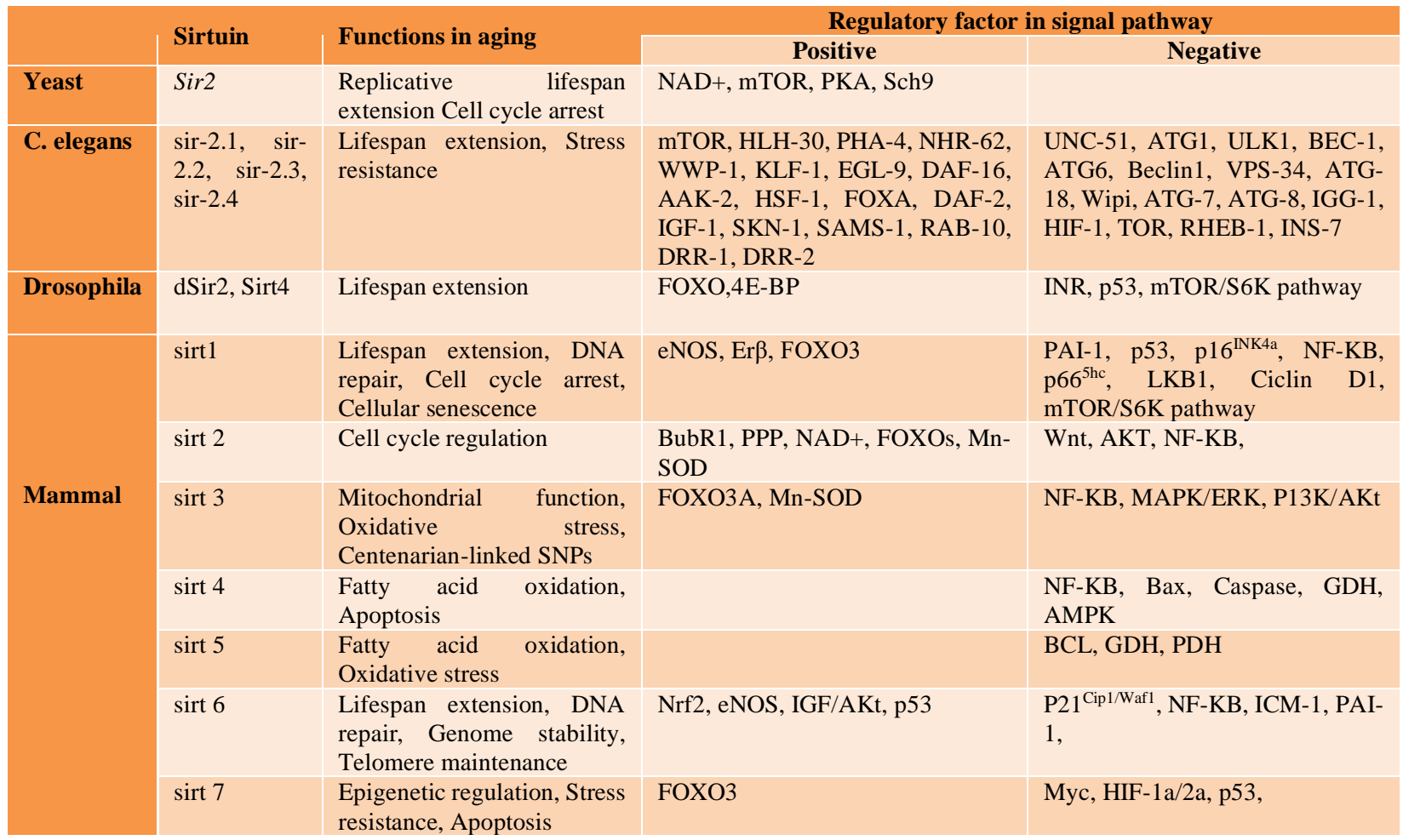

Among the mammalian sirtuins, sirtl has been the most extensively characterized for its role in aging. Although much of the attention has gone to sirtl and its protective effects against the onset of chronic diseases, its effect on longevity remains unconvincing. Sirtuins other than sirtl are also reported to exert a prolongevity effect. Recently, sirt 2 has been found to be a key modulator of ageing, and it extends lifespan in the BubR1 mice model[68]. Additionally, sirt3 is the only sirtuin that has been shown to be associated with human aging; some (but not all) studies have linked polymorphisms in the sirt3 genomic locus to survival in elderly individuals $[55,56$, 69, 70]. However, no pan- or tissue-specific transgenic animal models overexpressing sirt 3 to determine whether sirt 3 overexpression confers lifespan extension or protects against age-associated pathologies have been described in the literature currently, and some newer studies failed to confirm these correlations in other populations $[56,70]$. In contrast, recent work on sirt6 suggests that this sirtuin might hold the most potential for actual life-span extension [47]. Loss of sirt6 causes severe metabolic defects and rapid aging [71]. In addition, global sirt7 depletion contributes to premature ageing, especially in the backbone, white adipose tissue and the heart $[72,73]$.

However, it is clear that we are just starting to appreciate the importance of identifying specific processes in aging regulated by the different members of the sirtuin family in a tissue-, cell type-, and gene specific context. Thus, identifying these processes might be necessary to gain a better understanding of their role and fill in the current knowledge gaps in the field.

\section{Sirtuins and ageing-related diseases}

Although there has been emerging debate on the role of sirtuins in ageing and lifespan extension, mounting evidence suggests that sirtuins are indeed the critical modulators of ageing and aging-related diseases via different signalling pathways. The human sirtuin isoforms, sirt1-7, are considered attractive therapeutic targets for ageing-related diseases listed in table 3, including diabetes, metabolic syndrome, cardiomyopathies, non-alcoholic hepatic steatosis, hyperinsulinism-induced dyslipidaemia, chronic inflammation, neurodegenerative diseases, and some types of cancer [74, 75]. Here, we summarize and discuss some of the recent discoveries in sirtuins biology and their functions in age-related diseases. Table 4 lists some age-related diseases in elderly population

\section{Sirtuins and neurodegenerative disease}

Although the body's organ systems experience a general decline in function with age, perhaps the most emotionally and physically devastating decline is associated with the CNS. Impaired CNS function, with its effects on 
cognition, memory, hearing, balance, and motor control, can lead to a rapid loss of quality of life. In recent years, the risk of neurodegenerative disease (e.g., Alzheimer's disease (AD), Parkinson's disease (PD), Huntington's disease (HD), and others) has increased sharply with age [76]. Several studies have revealed the important roles of sirtuins in neuronal development and neurodegenerative disease [77, 78]. Though the ability of sirtuins to ameliorate CNS-specific disorders is still a very inchoate area of investigation, the initial findings offer significant promise.

Progress in understanding the neurobiological benefits of sirtl has been focused on animal models of different human CNS diseases. In mouse models of Alzheimer's disease, brain-specific knockout of sirtl caused a significant elevation in $\beta$-amyloid plaques and reactive gliosis [79]. Sirt1 also conferred neuroprotection in three different mouse models of Huntington's disease $[80,81]$. Brain-specific deletion of sirtl exacerbated the neurotoxicity associated with mutant huntingtin protein, whereas overexpression of sirtl attenuated the toxicity. In addition, in a mouse model of Parkinson's disease, overexpression of sirt 1 reduced $\alpha$-synuclein aggregates, reduced gliosis, and attenuated lethality [82]. In a mouse model of injury-induced axonal degeneration, $\mathrm{NAD}^{+}$ biosynthesis and its support of sirtl activity were shown to be essential in preventing axonal loss following axonal transection [83, 84].

Inhibition of sirt 2 by pharmacological and genetic means in invertebrate and cell culture models has suggested potential neuroprotective benefits [85]. Unfortunately, sirt2 knockout mice lacked a remarkable phenotype related to neurodegeneration [86], calling into question the effect of sirt 2 on neuronal health in mammals.

Less data is available for other sirtuins. It has been found that short-term $\mathrm{AD}$ treatment with extracellular A $\beta 1-42$ oligomers enhanced the expression of the sirt4 gene, but prolonged treatment affected all three mitochondrial isoforms (sirt3 to sirt5), suggesting that links between APP/A $\beta$ and sirtuins might be more complex, and possibly reciprocal [87].

Table 4. Some age-related diseases in elderly population.

\begin{tabular}{|ll|}
\hline $\begin{array}{l}\text { Neurodegenerative } \\
\text { diseases }\end{array}$ & $\begin{array}{l}\text { Presbyophrenia, Huntington's disease, Parkinson's disease, Alzheimer's } \\
\text { disease, Amyotrophic lateral sclerosis }\end{array}$ \\
\hline $\begin{array}{l}\text { Cardiovascular and } \\
\text { cerebrovascular diseases }\end{array}$ & $\begin{array}{l}\text { Hypertension, Coronary disease, Cardiomyopathies, Elder valvular heart } \\
\text { disease, Arrhythmia, Cardiac failure, Cerebral infraction, Atherosclerosis }\end{array}$ \\
\hline $\begin{array}{l}\text { Metabolic related } \\
\text { diseases }\end{array}$ & $\begin{array}{l}\text { Diabetes, Metabolic syndrome, Osteoporosis, Hyperinsulinism-induced } \\
\text { dyslipidaemia, Uarthritis, Non-alcoholic hepatic steatosis, }\end{array}$ \\
\hline Others & Scapulohumeral periarthritis, Chronic bronc, Chronic inflammation, Cancer \\
\hline
\end{tabular}

\section{Sirtuins and cardiovascular diseases}

In addition, aging results in well-defined phenotypic changes which lead the cardiovascular system to develop diseases even in the absence of traditional risk factors [88]. Sirtuins have been associated with vascular diseases in humans, such as carotid plaques [89], carotid intima media thickness [90], arterial stiffness [91], and plaque area and morphology [92].

Whole body augmentation of sirt 1 activity confers resistance to many cardiovascular sequelae associated with metabolic syndrome. Study indicated that endothelial sirtl age-dependent depletion or its inactivation is a frequent companion of many cardiovascular diseases (CVDs) [93]. Sirt1 is highly expressed in endothelial cells, and activation of sirtl in endothelial tissues may be beneficial in the protection of endothelial cell function with age [94]. Conversely, sirt1 insufficiency results in greater foam cell formation and atherosclerotic lesioning [95]. Age-related loss of sirt1 protein expression in human VSMC correlates with a loss of capacity for vascular repair, diminished stress response, and increased senescence [96, 97]. Sirtl appears to counteract atherosclerosis by inhibiting VSMC hypertrophy [98] and neointima formation and protecting against DNA damage, medial degeneration, and hypertension [99, 100]. In summary, sirtl acts as a cardioprotective molecule that protects from aging, induces resistance against hypertrophic and oxidative stresses, inhibits cardiomyocyte apoptosis, and regulates cardiac energy metabolism $[101,102]$. However, the role of sirtl on longevity and human cardiovascular diseases is not fully convincing, so further studies are needed.

Hashimoto-Komatsu et al. showed that sirt 2 mediates microtubule reorganization induced by Ang II and cyclic stretch in endothelial cells, suggesting that sirt2 is a key regulator of endothelial remodeling [103]. However, sirt2 knockout mice have no cardiac abnormalities. Thus, further studies are warranted to precisely define the role of sirt 2 in cardiac contractile function under physiological and pathological conditions. Sirt3 is necessary to prevent mitochondrial dysfunction and cardiac hypertrophy during ageing [104, 105]. Overexpression of sirt3 blunts cardiac hypertrophy by decreasing oxidative stress via 
upregulation of endogenous antioxidants (like Mn-SOD2 and catalase). Sirt4 is found to be specifically enriched in the heart, kidney, brain, and liver. Furthermore, sirt4 can also negatively modulate insulin secretion, fatty acid oxidation, and mitochondrial gene expression in cardiomyocytes and the liver, although the mechanism remains elusive and in vivo data are actually absent [106]. Variants in sirt5 gene have been found to be associated with the risk of carotid plaque development [96]. In addition, Liu et al. have demonstrated in vivo that sirt5 plays a critical role in regulating cell viability in cardiomyocytes [107]. Future studies are required to investigate the correlations between sirt 5 level and on the effect of sirt5 on various pathologic pathways of CVDs.

Based on the striking phenotype of sirt6 knockout mice, which are predisposed to accelerated senescence, significant researches have shown in vivo that sirt6 can also regulate cardiac hypertrophy and age-related cardiovascular alterations [108, 109]. Among nuclear sirtuins, sirtl and sirt6 play an important role in prevention and delay of CVDs [110]. In fact, sirt6 expression blocks the development of cardiac hypertrophy and heart failure [111, 112], whereas some data suggested that sirtl promoted cardiomyocyte hypertrophy [113]. To date, the molecular events through which sirt6 exerts a protective role at cardiovascular level, regulating the endothelial cell and cardiomyocyte response to stress, reducing oxidative stress and hyperglycemia, are still unclear. Vakhrusheva et al. have demonstrated that sirt7 plays an important role in preventing progressive functional deterioration of the heart [73]. Sirt7 deletion leads to various pathological changes in the heart, which further aggravates with age, including heart hypertrophy, fibrosis, lipofuscin accumulation and inflammatory cardiomyopathy.

However, there are many unsolved issues regarding the function of sirtuins at cardiovascular level, and undoubtedly, more work is needed to understand the role of the different sirtuins in cardiac and vascular cell biology before they can be considered as a valuable therapeutic target against age-related cardiovascular diseases.

\section{Sirtuins and metabolic diseases}

Furthermore, declines in basal metabolic rate and physical activity contribute to an elevated incidence of insulin resistance, obesity, and metabolic syndrome with age [114]. Sensing of the metabolic state and regulation of the sirtuin function and expression are critical components of the metabolic machinery. Thus, activation of pathways that restores insulin sensitivity and improves the utilization of glucose and fatty acids would be of benefit in stemming the pathologies associated with age-related metabolic dysfunction [115]. In the next review, we summarize an overview and update on the function of different sirtuin in metabolism, and further touch the correlation between each sirtuin and disorders of metabolism.

Many studies have indicated that sirtl is an important target for mitigating metabolic dysfunction. Sirtl is directly involved on metabolic pathways such as lipogenesis, stimulation of fatty acid $\beta$-oxidation, and gluconeogenesis. Its overexpression is thought to be beneficial and generates phenotypes in mice similar to calorie restriction conditions. All the major mitochondrial processes including the krebs cycle, the fatty acid metabolism, the antioxidant response, the amino acid catabolism, and so on, are regulated by the balance of N"lysine acetylation/deacetylation. Several transgenic models have shown that heightened sirtl activity protects against the metabolic derangement associated with obesity [116]. Sirt1 and sirtl activators can prevent and reverse insulin resistance and diabetic complications, and have been proven to be promising therapeutic targets for type 2 diabetes (T2D) [117-119]. In addition, the protective effects of sirt1 may occur through attenuation of inflammatory responses, as sirtl overexpression mitigates HFD-induced hepatic steatosis and adipose tissue specific inflammation $[120,121]$.

Compared to sirt1, sirt2 is abundant in adipocytes. Current evidence suggests a role for sirt 2 in regulating adipose tissue development and function. Sirt2 activates the PEPCK via deacetylation and enhances gluconeogenesis during times of glucose deprivation [122]. Meanwhile, recent studies have proposed that, with regard to insulin sensitivity, sirt2 may act in opposing roles in different tissues [123]. Thus, sirt2 activation may prove to be protective against obesity, and its role in metabolic homeostasis deserves further exploration.

Sirt3 may regulate cellular energy status both at transcriptional level in the nucleus and by posttranscriptional mechanisms in mitochondria, and its expression is higher in metabolically active tissues including brain, liver, heart, brown adipose tissue and skeletal muscle [124]. Sirt3 functions by activating important enzymes during CR, such as 3-hydroxy-3methylglutaryl- CoA synthase 2 for generation of ketones [125] and long chain acyl-CoA dehydrogenase for the oxidation of long-chain fatty acids [126]. Sirt3 also activates glutamate dehydrogenase (GDH), facilitating gluconeogenesis from amino acids[127]. In addition, sirt3 indirectly destabilizes the transcription factor HIF $1 \alpha$ and subsequently inhibits glycolysis and glucose oxidation [128]. Intriguingly, recent studies have shown that sirt3 levels in pancreatic islets are reduced in patients afflicted with type 2 diabetes [129], and sirt3 overexpression in pancreatic $\beta$-cells promotes insulin secretion and 
abrogates endoplasmic reticulum (ER) stress that is connected to $\beta$-cell dysfunction and apoptosis [130].

In contrast to sirt3, hepatic sirt4 expression declines slightly during caloric restriction (CR) and increases in genetic models of diabetes [34, 131, 132]. Little is known about the physiological relevance of sirt4 and its role in metabolism. Sirt4, initially reported as a unique ADP ribosyltransferase, appears to blunt insulin secretion by reducing GDH activity [133]. In addition to GDH, a diverse range of sirt4 targets are identified in the regulation of insulin secretion, including ADP/ATP carrier proteins, insulin-degrading enzymes, ANT2 and ANT3 [133]. Recently, Haigis and coworkers showed that sirt4 promoted lipid synthesis and inhibition of fatty acid oxidation by deacetylation of malonyl CoA decarboxylase [134].

In contrast to other sirtuins, sirt 5 displays deacetylase and $\mathrm{NAD}^{+}$dependent demalonylase and desuccinylase activities. Sirt5 facilitates glycolysis by demalonylating the glycolytic enzyme glyceraldehyde phosphate dehydrogenase (GAPDH) [38]. A recent study proposed that sirt5 might be positively correlated with insulin sensitivity, the biological significance of which still remains to be confirmed [135].

The indication of the connection between sirt6 and metabolism was first provided by Mostoslavsky et al. who showed that sirt6-deficient mice had a loss of subcutaneous fat, lymphopenia and acute hypoglycemia [136]. Conversely, one recent study revealed that sirt6 overexpression protects mice from diet-induced obesity, showing increased glucose tolerance and reduced fat accumulation [137]. In addition, sirt6 may positively mediate glucose stimulated insulin secretion and overexpression of sirt6 enhances insulin sensitivity in skeletal muscle and liver, which implicates that sirt6 may act as an attractive therapeutic target for T2D [138].

In addition, sirt7 knockout mice were resistant to glucose intolerance, and insulin sensitivity was improved in sirt7 knockout mice receiving a high-fat diet [46], revealing a novel role for sirt7 in glucose metabolism.

\section{Sirtuins and Cancer}

Based upon statistics from the National Cancer Institute, $54 \%$ of all cancer cases occur in people over the age of 65. Cancer is recognized as an age-related disease and occurs in an exponentially increasing pattern in elderly individuals. In recent years, cancer has become a grim challenge for us. Cancer seems to be one of the biggest hurdles in our way to longer and healthier ageing lives.

Currently, accumulating evidence has shown that the aberrant epigenetic activation of sirtuin signaling pathways contributes to tumor carcinogenesis and may be potential therapeutic targets for future treatments and biomarkers in predicting prognosis in cancers $[23,139]$. Interestingly, sirtuins seem to have a dual role in cancer [140]. On the one hand, some sirtuins help protect DNA from damage and oxidative stress, maintain genomic stability, limit replicative life-span, and protect organisms against cancer. On the other hand, some data suggest that the promotion of cell survival under stress conditions by sirtuins could be directly involved in tumorigenesis, as it would inhibit senescence and allow unchecked cell division [141].

The role of sirtuins, especially sirtl in carcinogenesis, appears to be opposing and complicated. Under normal conditions, in response to stress or to DNA damage, sirtl might promote cell survival via cell cycle arrest, DNA repair, or inhibition of apoptosis. If the stress signal becomes chronic or the levels of damage cross a certain threshold, sirtl could induce cell senescence and prevent carcinogenesis [116]. However, following chronic stress or DNA damage, the loss of a tumor suppressor or of any other checkpoint- related factor could cause an imbalance in these regulatory processes and induce sirtl overexpression beyond a critical limit. The aberrant overexpression of sirtl would in turn contribute to transformation and tumor formation by promoting cell growth and inhibiting apoptosis [142].

In fact, sirtl acts as a tumor keystone, and its level and action maintain a fine and delicate balance between suppression and promotion of oncogenesis. It is plausible that sirtl acts as a suppressor and then a promoter (or vice versa) depending on the stage and situation of tumourigenesis. The dual role of sirtuins in different cancers have has been summarized and shown in Table 5 . Studies have shown that sirtl is upregulated in many human cancer cell lines, as well as in tissues collected from patients suffering from various types of cancer (e.g., lung cancer, prostatic cancer, colon cancer, breast cancer, ovarian cancer, leukaemia, neuroblastomas, osteosarcomas, etc.), suggesting that sirtuins might be cancer therapeutic targets and the sirtl inhibition in cancer cells could possibly inhibit cancer cell growth [143-145]. Other research, however, points to a tumor suppressive role for sirt1. Certain cancer types, such as oral squamous cell carcinoma (OSCC), restoration of sirtl levels in these cells results in inhibition of tumor growth [146]. In other cancer mouse models, sirtl can protect against the development of intestinal tumors in a $\beta$-catenin-driven colon cancer model [147], sarcomas, lymphomas, teratomas, and carcinomas arising from deletion of p53 [148], HFD-induced hepatocarcinomas [116], and ageassociated spontaneous tumor development [116]. In addition, other studies reported only slightly elevated sirt 1 activity (in some thyroid cancers) or unchanged activity in some lung cancers, colon cancers, gastric cancers, urinary bladder cancers, and skin cancers [148]. 
Table 5. The dual role of sirtuins in different cancer.

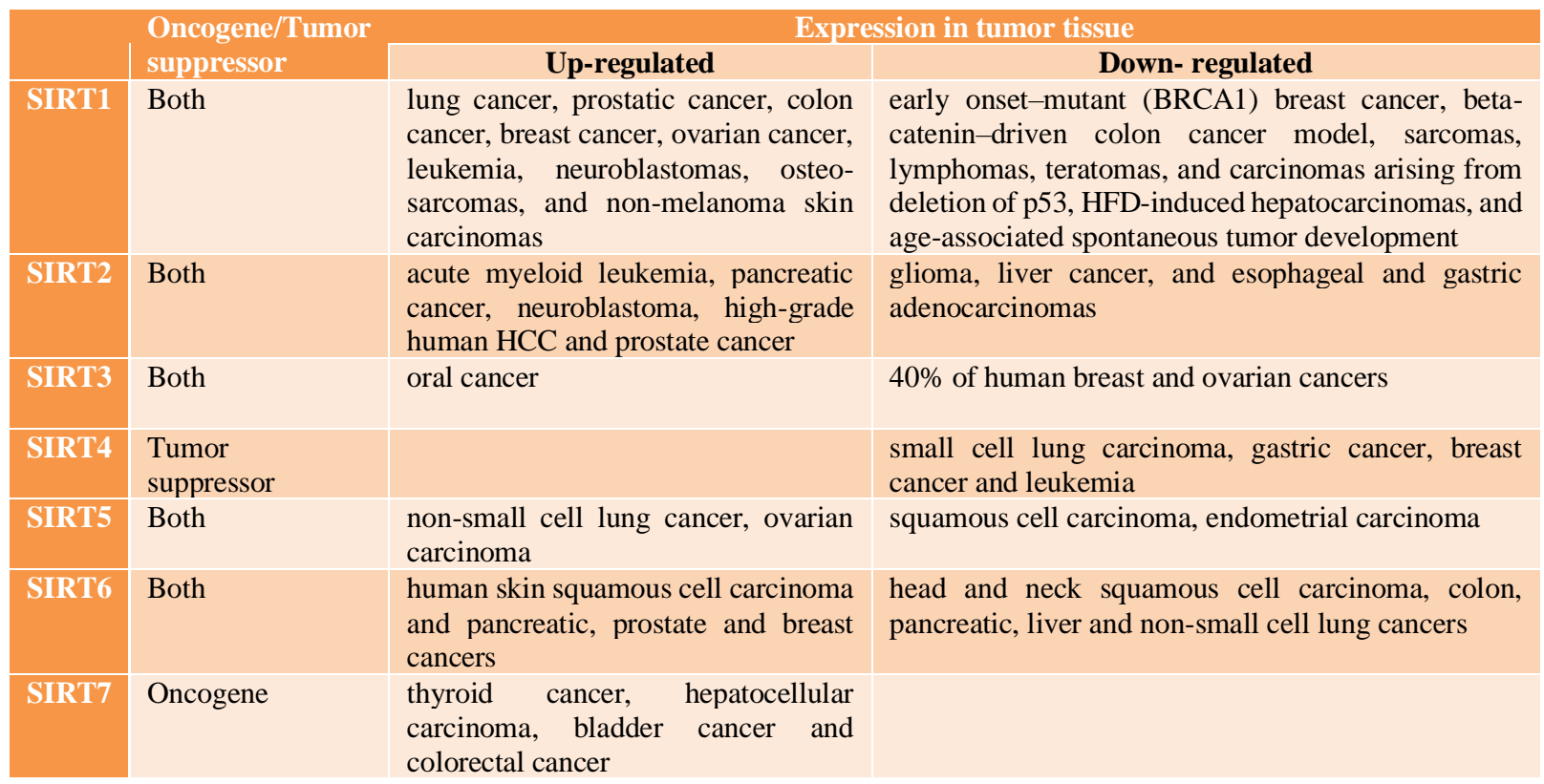

Similar to sirt1, sirt2 is either a positive or a negative regulator of the tumorigenic process. The expression of sirt 2 has been found downregulated in several cancers, such as gliomas, breast cancer, head and neck squamous cell carcinoma, non-small cell lung cancer, and esophageal adenocarcinoma, and elevated in others, such as neuroblastoma, pancreatic cancer, and acute myeloid leukemia $[149,150]$.

The case of sirt3 is more complex. Several studies indicate that sirt3 is a tumor suppressor, mainly through mechanisms linked to oxidative response, energetic balance, and metabolic regulation [11, 151]. Sirt3 expression is decreased in many human cancers, especially in $40 \%$ of human breast and ovarian cancers $[108,128]$. However, in specific cancer types, sirt 3 turns out to be an oncogene and promote tumorigenensis [152, 153].

Sirt4 mRNA levels were reduced in several human cancers, such as small cell lung carcinoma [154], gastric cancer [155], breast cancer and leukemia [156]. Lower sirt4 expression is associated with shorter survival time in lung tumor patients [157]. A recent study has also shown that sirt4 is a crucial regulator of stress resistance in cancer cells and sirt4 loss sensitizes cells to DNA damage or ER stress [158].

Similar to other sirtuins, sirt 5 has been considered as a potential oncogene or tumor suppressor. Sirt5 acts as a potential oncogene, and is overexpressed in non-small cell lung cancer [159] and ovarian carcinoma [160]. However, sirt5 also emerged as a tumor suppressor in squamous cell carcinoma [161] and endometrial carcinoma [162].
Sirt6 is thought to be a significant tumor suppressor protein (TSP), given its major role as a guardian of genome stability[163, 164]. Sirt6 overexpression induces intense apoptosis in cancer cells but not in normal cells, which makes it an attractive "target" for future antineoplastic medications [165]. In addition, as with sirt1, sirt6 plays both tumor suppressing and promoting roles. sirt6 expression is downregulated in head and neck squamous cell carcinoma, and colon, pancreatic, liver and non-small cell lung cancers $[161,166,167]$. Conversely, increased sirt6 expression has been reported in human skin squamous cell carcinoma and pancreatic, prostate and breast cancers, whose high expression suggests a poor prognosis and chemotherapy resistance[168-171].

Although sirt7 has received comparatively less attention than other sirtuins, sirt7 appears to have been regarded as a potential oncogene for its upregulation in all the cancer types studied so far, such as thyroid cancer, hepatocellular carcinoma, bladder cancer and colorectal cancer [172-174]. Sirt7 can contribute to the maintenance of a transformed cell phenotype in tumor cells by suppressing the expression of some TSPs [15]. However, sirt7 does not contribute to the initiation of carcinogenesis, which has been experimentally proven, as no correlation between sirt7 upregulation in normal cells and their susceptibility to transformation has been found $[6,15]$.

\section{Activators and inhibitors of sirtuins}

As the area of molecular science consolidates and advances, the sirtuin family members are gaining 
significance in human biology and disease. All of the above findings suggest that sirtuins show strong potential to become valuable predictive and prognostic markers for disease and therapeutic targets for the management of a variety of cancer types and other age-related diseases.
Therefore, in the following review, we summarize the common activators and small molecule inhibitors of sirtuins in relieving aging symptoms and age-related diseases, which is shown in table 6 .

Table 6. Activators and inhibitors of sirtuins.

\begin{tabular}{|c|c|c|}
\hline & Activators & inhibitors \\
\hline SIRT1 & $\begin{array}{lll}\text { Piceatannol, } & \text { Resveratrol, } & \text { SRT1720. } \\
\text { SRT2104, 1,4-DHP derivative, } & \text { SRT1460, } \\
\text { SRT2183 } & \end{array}$ & Ex-527, ELT-11c \\
\hline SIRT2 & 1,4-DHP derivative & $\begin{array}{l}\text { AGK2, 3'-(3-fluoro-phenethyloxy)-2-anilino- } \\
\text { benzamide, SirReal2, Compound 15e, } \\
\text { UBCS0137, ELT-11c, Compound 28e, AEM2, } \\
\text { TM, Chroman-4-one analogue, RK-9123016, } \\
\text { NPD11033 }\end{array}$ \\
\hline SIRT3 & Piceatannol, Resveratrol, 1,4-DHP derivative & Compound 8, ELT-11c, SDX-437 \\
\hline SIRT4 & & \\
\hline SIRT5 & Piceatannol, Resveratrol, UBCS039 & \\
\hline SIRT6 & UBCS039 & Compound 1 \\
\hline
\end{tabular}

\section{Small molecule activators of sirtuins}

Dietary restriction (DR)/CR (the reduction of calorie intake without causing malnutrition) is the only known intervention able to increase the lifespan in many species, including yeast, fruit flies, nematodes, fish, rats, mice, hamsters and dogs $[175,176]$ and possibly even primates [177].

Since sirtuin is commonly believed to mediate the beneficial effects of CR, the activators of sirtuins are considered to mimic these beneficial effects and are hence attractive therapeutics for age-related diseases [178]. The search for molecules those activates sirtuins began more than a decade ago. These sirtuin-activating compounds (STACs) are mainly divided into two categories. One is the use of exogenous activators, the other is replenishment of the cellular $\mathrm{NAD}^{+}[75,179]$.The first STACs were discovered for sirtl in 2003, and the most potent of which was resveratrol. This initial discovery was important because it proved that allosteric activation of sirtuins was possible [179]. Treatment with resveratrol and its derivatives brought some beneficial effects of sirtl induction without applying CR [180, 181]. Moreover, studies have shown that the sirtuin activator resveratrol has chemo preventive activity against various cancers, including leukemia, DMBA-induced mammary tumors in rats, skin cancer, and prostate cancer [182-184]. Following the discovery of resveratrol, a few researchers tried to find other selective activators [181]. Highthroughput screening and medicinal chemical efforts have since identified more than 14,000 STACs from a dozen chemical classes, including several classes of plant derived metabolites such as flavones, stilbenes, chalcones, and anthocyanidins, which directly activate sirt1 in vitro [179]. Synthetic STACs include a number of agents such as imidazothiazoles (e.g., SRT1720) [185], thiazolopyridines (e.g., STAC-2), benzimidazoles (e.g., STAC-5), bridged ureas (e.g., STAC-9 ), cilostazol [186], paeonol [187], statins [188], hydrogen sulfide [189, 190] and persimmon [191]. All of these chemical classes activate sirtl by lowering the $\mathrm{Km}$ value of the substrate through a K-type allosteric activation mechanism[192, 193]. In addition, there are some natural anti-ageing compounds, such as quercetin, butein, fisetin, kaempferol, catechins and proanthocyanidins [194].

An alternative approach to activating sirtuins is to regulate $\mathrm{NAD}^{+}$level by activating enzymes involved in biosynthesis of NAD or by inhibiting the CD38 NAD hydrolase [195-197].It has been known since 2003 that upregulation of the NAD salvage pathway, which recycles $\mathrm{NAD}^{+}$from NAM, can extend lifespan and mimic calorie restriction in yeast $[198,199]$. NAD-boosting molecules constitute a newer class of STACs those are gaining attention as a way to restore $\mathrm{NAD}^{+}$levels in elderly individuals and potentially activate all seven sirtuins with a single compound. Examples of NAD-boosting molecules include NMN, nicotinamide riboside67 [200203], and inhibitors of CD38 such as apigenin [196], quercetin [196] and GSK 897-78c [204]. In addition, targeting the enzymes that regulate $\mathrm{NAD}^{+}$levels, such as CD38, CD157 and NAMPT, may also be worth exploring for their therapeutic potential. Moreover, malate dehydrogenase, MDH1, which is involved in energy metabolism and reduces NAD+ to NADH during its catalytic reaction, also plays a critical role in cellular senescence. 


\section{Small molecule inhibitors of sirtuins}

The inhibition of sirtuins has attracted more interest as a potential therapeutic anticancer strategy. Here, the fundamental principle of developing inhibitors is that they should have two characteristics: they should be potent and selective. The mechanism of a potent inhibitor is as follows: combining of the inhibitor and the sirtuin may be easier than that of $\mathrm{N} \varepsilon$-acyl-lysine and the sirtuin, and the inhibitors may be processed by the sirtuin into a noncatalytic intermediate which can bind tightly to the active site of the sirtuin to prevent the normal binding and processing of the substrate [205]. A selective inhibitor should perfectly inhibit one certain sirtuin, for example sirt2, while not reacting with other sirtuins. Based on these 2 principles, there are some inhibitors already designed, such as NAM and thioacyllysine-containing compounds. However, there are still limits for such inhibitors.

Except for the mechanism-based inhibitor discussed above, there is another common way to develop an inhibitor for sirtuin, which is by chemical library screening. In this way, thousands of molecules can be screened. Of these screened molecules, there are 5 compounds potent and selective enough, including sirtinol and its analogues, splitomicin and its derivatives, indole derivatives, and tenovin and its analogues, to presumably work by noncovalently binding to the sirtuin active site and blocking substrate binding.

Compound 6 was found to be a highly potent inhibitor of the deacetylation reaction catalysed by sirtl. Compound 6 may have much less inhibitory effect on reactions catalysed by sirt 2 and sirt 3 compared with sirtl. SirReal 2 and Compound 7 were screened from an internal compound library, and were demonstrated to be potent sirt2 inhibitors [206, 207]. Compound 8 is another potent and selective sirt2 inhibitor. X-ray analysis showed that when this compound binds to the active domain of sirt2, it may form a rigid cyclic structure by intramolecular hydrogen bonding. Therefore, it may tightly bind with sirt2, highly potently and selectively inhibiting the activity of sirt2 [205]. In addition, AK-7 is a brainpermeable selective sirt2 inhibitor. It is neuroprotective in vitro, by reducing polyglutamine inclusions and cholesterol levels in neurons [208]. Tenovin-6, salermide and benzodeazaoxaflavin are small-molecule inhibitors of sirtl and sirt2 [209, 210]. Suramin inhibits sirt5 by binding into the $\mathrm{B}$ - and $\mathrm{C}$-pockets of the $\mathrm{NAD}^{+}$binding site as well as to the substrate-binding site [211]. In total, segmented inhibition or activation of sirtuin activity might confer therapeutic potentials in the future, mainly because of its double-edged sword effects in cancer cells.

In addition, Natural compounds present in the diet, classed as functional food/nutrients, are a great promise for health and longevity promotion and prevention of agerelated chronic diseases [212]. Such compounds are nontoxic, easy to use and commonly available and could be included into a normal diet for long lasting supplementation. Several reports emphasized that dietary supplementation of polyphenols may protect against neurodegenerative, cardiovascular, inflammatory, metabolic diseases and cancer by enhancing sirtl deacetylase activity. However, in humans, the therapeutic and pharmacological potential of these natural compounds remains to be validated in clinical conditions.

\section{Implications and future perspectives}

Since the discovery of the yeast Sir2, sirtuins have been focused on their functions in ageing and age-related disease. Accumulating studies have revealed that sirtuins exert profound protective functions against ageing-related pathologies and the degeneration of tissues and organs in elderlyindividuals. Their multivalent roles in blocking the development of ageing and ageing-related diseases further mark them as promising targets for developing interventions for several age-associated pathologies.

The intense efforts in the past $\sim 15$ years to develop isoform specific small molecule modulators of the sirtuins have yielded key insights into the pathophysiological roles of sirtuins and have seen great strides in understanding the enzymatic reaction mechanisms. Initial drug development efforts focused on sirt1 and sirt 2 have yielded a number of potent sirt 2 inhibitors and sirt 1 activators, which have now been passed the first clinical trials, with evidence of safety and efficacy.

However, there is little standardization of the disease models currently used to study sirtuin therapeutic biology, leading to contradictory reports with limited crossvalidation of the findings. There is still a long way to go for a molecule to be applied in treatment, with hurdles of regarding side effects, stability, and selectivity. The field of sirtuin modulators has clearly matured into an exciting path of drug development that holds the promise for treating common and rare diseases, with considerable unmet demand.

\section{Acknowledgments}

This work was supported by National Natural Science Foundation of China (81471404 to L.M.H., 81772949 to T.J.T.); Clinical Medicine Plus X - Young Scholars Project (BMU2018MX005, Peking University. And We thank Mingtai Chen (Affiliated Hospital of Jining Medical University, Central Laboratory) for advice during the preparation of this manuscript. 


\section{Competing interests}

The authors declare that they have no competing interests.

\section{References}

[1] Klar AJ, Fogel S, Macleod K (1979). MAR1-a Regulator of the HMa and HMalpha Loci in SACCHAROMYCES CEREVISIAE. Genetics, 93:3750.

[2] Michan S, Sinclair D (2007). Sirtuins in mammals: insights into their biological function. Biochem $\mathrm{J}$, 404:1-13.

[3] Kaeberlein M, McVey M, Guarente L (1999). The SIR2/3/4 complex and SIR2 alone promote longevity in Saccharomyces cerevisiae by two different mechanisms. Genes Dev, 13:2570-2580.

[4] Vaquero A (2009). The conserved role of sirtuins in chromatin regulation. Int J Dev Biol, 53:303-322.

[5] Frye RA (2000). Phylogenetic classification of prokaryotic and eukaryotic Sir2-like proteins. Biochem Biophys Res Commun, 273:793-798.

[6] Michishita E, Park JY, Burneskis JM, Barrett JC, Horikawa I (2005). Evolutionarily conserved and nonconserved cellular localizations and functions of human SIRT proteins. Mol Biol Cell, 16:4623-4635.

[7] Tanno M, Sakamoto J, Miura T, Shimamoto K, Horio Y (2007). Nucleocytoplasmic shuttling of the NAD+dependent histone deacetylase SIRT1. J Biol Chem, 282:6823-6832.

[8] North BJ, Marshall BL, Borra MT, Denu JM, Verdin E (2003). The human Sir2 ortholog, SIRT2, is an NAD+dependent tubulin deacetylase. Mol Cell, 11:437-444.

[9] Jing E, Gesta S, Kahn CR (2007). SIRT2 regulates adipocyte differentiation through FoxO1 acetylation/deacetylation. Cell Metab, 6:105-114.

[10] He W, Newman JC, Wang MZ, Ho L, Verdin E (2012). Mitochondrial sirtuins: regulators of protein acylation and metabolism. Trends Endocrinol Metab, 23:467-476

[11] Verdin E, Hirschey MD, Finley LW, Haigis MC (2010). Sirtuin regulation of mitochondria: energy production, apoptosis, and signaling. Trends Biochem Sci, 35:669675.

[12] Michishita E, McCord RA, Berber E, Kioi M, PadillaNash H, Damian M, et al. (2008). SIRT6 is a histone H3 lysine 9 deacetylase that modulates telomeric chromatin. Nature, 452:492-496.

[13] Ford E, Voit R, Liszt G, Magin C, Grummt I, Guarente L (2006). Mammalian Sir2 homolog SIRT7 is an activator of RNA polymerase I transcription. Genes Dev, 20:1075-1080.

[14] Dang W (2014). The controversial world of sirtuins. Drug Discov Today Technol, 12:e9-e17.

[15] Barber MF, Michishita-Kioi E, Xi Y, Tasselli L, Kioi M, Moqtaderi Z, et al. (2012). SIRT7 links H3K18 deacetylation to maintenance of oncogenic transformation. Nature, 487:114-118.

[16] Kumar S, Lombard DB (2018). Functions of the sirtuin deacylase SIRT5 in normal physiology and pathobiology. Crit Rev Biochem Mol Biol, 53:311-334.

[17] Canto C, Sauve AA, Bai P (2013). Crosstalk between poly(ADP-ribose) polymerase and sirtuin enzymes. Mol Aspects Med, 34:1168-1201.

[18] Imai S, Armstrong CM, Kaeberlein M, Guarente L (2000). Transcriptional silencing and longevity protein Sir2 is an NAD-dependent histone deacetylase. Nature, 403:795-800

[19] Jiang H, Khan S, Wang Y, Charron G, He B, Sebastian C, et al. (2013). SIRT6 regulates TNF-alpha secretion through hydrolysis of long-chain fatty acyl lysine. Nature, 496:110-113.

[20] Du J, Zhou Y, Su X, Yu JJ, Khan S, Jiang H, et al. (2011). Sirt5 is a NAD-dependent protein lysine demalonylase and desuccinylase. Science, 334:806-809.

[21] Tan M, Peng C, Anderson KA, Chhoy P, Xie Z, Dai L, et al. (2014). Lysine glutarylation is a protein posttranslational modification regulated by SIRT5. Cell Metab, 19:605-617.

[22] Peng C, Lu Z, Xie Z, Cheng Z, Chen Y, Tan M, et al. (2011). The first identification of lysine malonylation substrates and its regulatory enzyme. Mol Cell Proteomics, 10:M111 012658.

[23] Bosch-Presegue L, Vaquero A (2011). The dual role of sirtuins in cancer. Genes Cancer, 2:648-662.

[24] Luo H, Chiang HH, Louw M, Susanto A, Chen D (2017). Nutrient Sensing and the Oxidative Stress Response. Trends Endocrinol Metab, 28:449-460.

[25] Rahman S, Islam R (2011). Mammalian Sirt1: insights on its biological functions. Cell Commun Signal, 9:11.

[26] Feldman JL, Baeza J, Denu JM (2013). Activation of the protein deacetylase SIRT6 by long-chain fatty acids and widespread deacylation by mammalian sirtuins. J Biol Chem, 288:31350-31356.

[27] Serrano L, Martinez-Redondo P, Marazuela-Duque A, Vazquez BN, Dooley SJ, Voigt P, et al. (2013). The tumor suppressor SirT2 regulates cell cycle progression and genome stability by modulating the mitotic deposition of H4K20 methylation. Genes Dev, 27:639653.

[28] Houtkooper RH, Pirinen E, Auwerx J (2012). Sirtuins as regulators of metabolism and healthspan. Nat Rev Mol Cell Biol, 13:225-238.

[29] Wang F, Tong Q (2009). SIRT2 suppresses adipocyte differentiation by deacetylating FOXO1 and enhancing FOXO1's repressive interaction with PPARgamma. Mol Biol Cell, 20:801-808.

[30] Rothgiesser KM, Erener S, Waibel S, Luscher B, Hottiger MO (2019). Correction: SIRT2 regulates NFkappaB-dependent gene expression through deacetylation of p65 Lys310 (doi:10.1242/jcs.073783). J Cell Sci, 132.

[31] Lombard DB, Zwaans BM (2014). SIRT3: as simple as it seems? Gerontology, 60:56-64.

[32] Kanfi Y, Shalman R, Peshti V, Pilosof SN, Gozlan YM, Pearson KJ, et al. (2008). Regulation of SIRT6 protein levels by nutrient availability. FEBS Lett, 582:543-548.

[33] Shi T, Wang F, Stieren E, Tong Q (2005). SIRT3, a mitochondrial sirtuin deacetylase, regulates mitochondrial function and thermogenesis in brown 
adipocytes. J Biol Chem, 280:13560-13567.

[34] Haigis MC, Mostoslavsky R, Haigis KM, Fahie K, Christodoulou DC, Murphy AJ, et al. (2006). SIRT4 inhibits glutamate dehydrogenase and opposes the effects of calorie restriction in pancreatic beta cells. Cell, 126:941-954.

[35] Kumar S, Lombard DB (2017). For Certain, SIRT4 Activities! Trends Biochem Sci, 42:499-501.

[36] Ho L, Titus AS, Banerjee KK, George S, Lin W, Deota $\mathrm{S}$, et al. (2013). SIRT4 regulates ATP homeostasis and mediates a retrograde signaling via AMPK. Aging (Albany NY), 5:835-849.

[37] Park J, Chen Y, Tishkoff DX, Peng C, Tan M, Dai L, et al. (2013). SIRT5-mediated lysine desuccinylation impacts diverse metabolic pathways. Mol Cell, 50:919930.

[38] Nishida Y, Rardin MJ, Carrico C, He W, Sahu AK, Gut P, et al. (2015). SIRT5 Regulates both Cytosolic and Mitochondrial Protein Malonylation with Glycolysis as a Major Target. Mol Cell, 59:321-332.

[39] Dominy JE, Jr., Lee Y, Jedrychowski MP, Chim H, Jurczak MJ, Camporez JP, et al. (2012). The deacetylase Sirt6 activates the acetyltransferase GCN5 and suppresses hepatic gluconeogenesis. Mol Cell, 48:900-913.

[40] Gertler AA, Cohen HY (2013). SIRT6, a protein with many faces. Biogerontology, 14:629-639.

[41] Beauharnois JM, Bolivar BE, Welch JT (2013). Sirtuin 6: a review of biological effects and potential therapeutic properties. Mol Biosyst, 9:1789-1806.

[42] Grummt I, Pikaard CS (2003). Epigenetic silencing of RNA polymerase I transcription. Nat Rev Mol Cell Biol, 4:641-649.

[43] Li L, Shi L, Yang S, Yan R, Zhang D, Yang J, et al. (2016). SIRT7 is a histone desuccinylase that functionally links to chromatin compaction and genome stability. Nat Commun, 7:12235.

[44] Osborne TB, Mendel LB, Ferry EL (1917). The Effect of Retardation of Growth Upon the Breeding Period and Duration of Life of Rats. Science, 45:294-295.

[45] McCay CM, Crowell MF, Maynard LA (1989). The effect of retarded growth upon the length of life span and upon the ultimate body size. 1935. Nutrition, 5:155171; discussion 172.

[46] Burnett C, Valentini S, Cabreiro F, Goss M, Somogyvari M, Piper MD, et al. (2011). Absence of effects of Sir2 overexpression on lifespan in $\mathrm{C}$. elegans and Drosophila. Nature, 477:482-485.

[47] Kanfi Y, Naiman S, Amir G, Peshti V, Zinman G, Nahum L, et al. (2012). The sirtuin SIRT6 regulates lifespan in male mice. Nature, 483:218-221.

[48] Kapahi P, Kaeberlein M, Hansen M (2017). Dietary restriction and lifespan: Lessons from invertebrate models. Ageing Res Rev, 39:3-14.

[49] Watroba M, Szukiewicz D (2016). The role of sirtuins in aging and age-related diseases. Adv Med Sci, 61:5262.

[50] Toiber D, Sebastian C, Mostoslavsky R (2011). Characterization of nuclear sirtuins: molecular mechanisms and physiological relevance. Handb Exp
Pharmacol, 206:189-224.

[51] Jeong J, Juhn K, Lee H, Kim SH, Min BH, Lee KM, et al. (2007). SIRT1 promotes DNA repair activity and deacetylation of Ku70. Exp Mol Med, 39:8-13.

[52] Oberdoerffer P, Michan S, McVay M, Mostoslavsky R, Vann J, Park SK, et al. (2008). SIRT1 redistribution on chromatin promotes genomic stability but alters gene expression during aging. Cell, 135:907-918.

[53] D'Onofrio N, Servillo L, Balestrieri ML (2018). SIRT1 and SIRT6 Signaling Pathways in Cardiovascular Disease Protection. Antioxid Redox Signal, 28:711-732. [54] Alcendor RR, Gao S, Zhai P, Zablocki D, Holle E, Yu $\mathrm{X}$, et al. (2007). Sirt1 regulates aging and resistance to oxidative stress in the heart. Circ Res, 100:1512-1521.

[55] Bellizzi D, Rose G, Cavalcante P, Covello G, Dato S, De Rango F, et al. (2005). A novel VNTR enhancer within the SIRT3 gene, a human homologue of SIR2, is associated with survival at oldest ages. Genomics, 85:258-263.

[56] Lescai F, Blanche H, Nebel A, Beekman M, Sahbatou M, Flachsbart F, et al. (2009). Human longevity and 11p15.5: a study in 1321 centenarians. Eur J Hum Genet, 17:1515-1519.

[57] Tissenbaum HA, Guarente L (2001). Increased dosage of a sir-2 gene extends lifespan in Caenorhabditis elegans. Nature, 410:227-230.

[58] Viswanathan M, Kim SK, Berdichevsky A, Guarente L (2005). A role for SIR-2.1 regulation of ER stress response genes in determining C. elegans life span. Dev Cell, 9:605-615.

[59] Berdichevsky A, Viswanathan M, Horvitz HR, Guarente L (2006). C. elegans SIR-2.1 interacts with 14-3-3 proteins to activate DAF-16 and extend life span. Cell, 125:1165-1177.

[60] Wang Y, Tissenbaum HA (2006). Overlapping and distinct functions for a Caenorhabditis elegans SIR2 and DAF-16/FOXO. Mech Ageing Dev, 127:48-56.

[61] Liang F, Kume S, Koya D (2009). SIRT1 and insulin resistance. Nat Rev Endocrinol, 5:367-373.

[62] Zhang J (2007). The direct involvement of SirT1 in insulin-induced insulin receptor substrate- 2 tyrosine phosphorylation. J Biol Chem, 282:34356-34364.

[63] Curtis R, O'Connor G, DiStefano PS (2006). Aging networks in Caenorhabditis elegans: AMP-activated protein kinase (aak-2) links multiple aging and metabolism pathways. Aging Cell, 5:119-126.

[64] Price NL, Gomes AP, Ling AJ, Duarte FV, MartinMontalvo A, North BJ, et al. (2012). SIRT1 is required for AMPK activation and the beneficial effects of resveratrol on mitochondrial function. Cell Metab, 15:675-690.

[65] Berdichevsky A, Nedelcu S, Boulias K, Bishop NA, Guarente L, Horvitz HR (2010). 3-Ketoacyl thiolase delays aging of Caenorhabditis elegans and is required for lifespan extension mediated by sir-2.1. Proc Natl Acad Sci U S A, 107:18927-18932.

[66] Rizki G, Iwata TN, Li J, Riedel CG, Picard CL, Jan M, et al. (2011). The evolutionarily conserved longevity determinants HCF-1 and SIR-2.1/SIRT1 collaborate to regulate DAF-16/FOXO. PLoS Genet, 7:e1002235. 
[67] Mouchiroud L, Houtkooper RH, Moullan N, Katsyuba E, Ryu D, Canto C, et al. (2013). The NAD(+)/Sirtuin Pathway Modulates Longevity through Activation of Mitochondrial UPR and FOXO Signaling. Cell, 154:430-441.

[68] Cosentino C, Mostoslavsky R (2014). Sirtuin to the rescue: SIRT2 extends life span of BubR 1 mice. EMBO J, 33:1417-1419.

[69] Bellizzi D, Dato S, Cavalcante P, Covello G, Di Cianni F, Passarino G, et al. (2007). Characterization of a bidirectional promoter shared between two human genes related to aging: SIRT3 and PSMD13. Genomics, 89:143-150.

[70] Rose G, Dato S, Altomare K, Bellizzi D, Garasto S, Greco V, et al. (2003). Variability of the SIRT3 gene, human silent information regulator Sir2 homologue, and survivorship in the elderly. Exp Gerontol, 38:10651070 .

[71] Zhang W, Wan H, Feng G, Qu J, Wang J, Jing Y, et al. (2018). SIRT6 deficiency results in developmental retardation in cynomolgus monkeys. Nature, 560:661665.

[72] Vakhrusheva O, Braeuer D, Liu Z, Braun T, Bober E (2008). Sirt7-dependent inhibition of cell growth and proliferation might be instrumental to mediate tissue integrity during aging. J Physiol Pharmacol, 59 Suppl 9:201-212.

[73] Vakhrusheva O, Smolka C, Gajawada P, Kostin S, Boettger T, Kubin T, et al. (2008). Sirt7 increases stress resistance of cardiomyocytes and prevents apoptosis and inflammatory cardiomyopathy in mice. Circ Res, 102:703-710.

[74] Imai S, Guarente L (2010). Ten years of NADdependent SIR2 family deacetylases: implications for metabolic diseases. Trends Pharmacol Sci, 31:212-220.

[75] Imai S, Guarente L (2014). NAD + and sirtuins in aging and disease. Trends Cell Biol, 24:464-471.

[76] Brown RC, Lockwood AH, Sonawane BR (2005). Neurodegenerative diseases: an overview of environmental risk factors. Environ Health Perspect, 113:1250-1256.

[77] Herskovits AZ, Guarente L (2014). SIRT1 in neurodevelopment and brain senescence. Neuron, 81:471-483.

[78] Cacabelos R, Carril JC, Cacabelos N, Kazantsev AG, Vostrov AV, Corzo L, et al. (2019). Sirtuins in Alzheimer's Disease: SIRT2-Related GenoPhenotypes and Implications for PharmacoEpiGenetics. Int $\mathrm{J}$ Mol Sci, 20.

[79] (2014). Retraction notice to: SIRT1 suppresses betaamyloid production by activating the alpha-secretase gene ADAM10. Cell, 158:959.

[80] Jeong H, Cohen DE, Cui L, Supinski A, Savas JN, Mazzulli JR, et al. (2011). Sirtl mediates neuroprotection from mutant huntingtin by activation of the TORC1 and CREB transcriptional pathway. Nat Med, 18:159-165.

[81] Jiang M, Wang J, Fu J, Du L, Jeong H, West T, et al. (2011). Neuroprotective role of Sirt1 in mammalian models of Huntington's disease through activation of multiple Sirt1 targets. Nat Med, 18:153-158.

[82] Donmez G, Arun A, Chung CY, McLean PJ, Lindquist S, Guarente L (2012). SIRT1 protects against alphasynuclein aggregation by activating molecular chaperones. J Neurosci, 32:124-132.

[83] Sasaki Y, Araki T, Milbrandt J (2006). Stimulation of nicotinamide adenine dinucleotide biosynthetic pathways delays axonal degeneration after axotomy. J Neurosci, 26:8484-8491.

[84] Araki T, Sasaki Y, Milbrandt J (2004). Increased nuclear NAD biosynthesis and SIRT1 activation prevent axonal degeneration. Science, 305:1010-1013.

[85] Luthi-Carter R, Taylor DM, Pallos J, Lambert E, Amore A, Parker A, et al. (2010). SIRT2 inhibition achieves neuroprotection by decreasing sterol biosynthesis. Proc Natl Acad Sci U S A, 107:7927-7932.

[86] Bobrowska A, Donmez G, Weiss A, Guarente L, Bates $G$ (2012). SIRT2 ablation has no effect on tubulin acetylation in brain, cholesterol biosynthesis or the progression of Huntington's disease phenotypes in vivo. PLoS One, 7:e34805.

[87] Jesko H, Wencel P, Strosznajder RP, Strosznajder JB (2017). Sirtuins and Their Roles in Brain Aging and Neurodegenerative Disorders. Neurochem Res, 42:876890.

[88] Favero G, Franceschetti L, Rodella LF, Rezzani R (2015). Sirtuins, aging, and cardiovascular risks. Age (Dordr), 37:9804.

[89] Dong C, Della-Morte D, Wang L, Cabral D, Beecham A, McClendon MS, et al. (2011). Association of the sirtuin and mitochondrial uncoupling protein genes with carotid plaque. PLoS One, 6:e27157.

[90] Della-Morte D, Dong C, Bartels S, Cabral D, Blanton SH, Sacco RL, et al. (2012). Association of the sirtuin and mitochondrial uncoupling protein genes with carotid intima-media thickness. Transl Res, 160:389390.

[91] Della-Morte D, Dong C, Beecham A, Wang L, Cabral D, Markert MS, et al. (2015). Relationship between sirtuin and mitochondrial uncoupling protein genes and carotid artery stiffness. Transl Res, 165:358-359.

[92] Dong C, Della-Morte D, Cabral D, Wang L, Blanton SH, Seemant C, et al. (2015). Sirtuin/uncoupling protein gene variants and carotid plaque area and morphology. Int J Stroke, 10:1247-1252.

[93] Chen J, Xavier S, Moskowitz-Kassai E, Chen R, Lu CY, Sanduski K, et al. (2012). Cathepsin cleavage of sirtuin 1 in endothelial progenitor cells mediates stressinduced premature senescence. Am J Pathol, 180:973983.

[94] Zhang QJ, Wang Z, Chen HZ, Zhou S, Zheng W, Liu G, et al. (2008). Endothelium-specific overexpression of class III deacetylase SIRT1 decreases atherosclerosis in apolipoprotein E-deficient mice. Cardiovasc Res, 80:191-199.

[95] Stein S, Lohmann C, Schafer N, Hofmann J, Rohrer L, Besler C, et al. (2010). SIRT1 decreases Lox-1mediated foam cell formation in atherogenesis. Eur Heart J, 31:2301-2309.

[96] D'Onofrio N, Vitiello M, Casale R, Servillo L, Giovane 
A, Balestrieri ML (2015). Sirtuins in vascular diseases: Emerging roles and therapeutic potential. Biochim Biophys Acta, 1852:1311-1322.

[97] Thompson AM, Wagner R, Rzucidlo EM (2014). Agerelated loss of SirT1 expression results in dysregulated human vascular smooth muscle cell function. Am $\mathrm{J}$ Physiol Heart Circ Physiol, 307:H533-541.

[98] Cardellini M, Menghini R, Martelli E, Casagrande V, Marino A, Rizza S, et al. (2009). TIMP3 is reduced in atherosclerotic plaques from subjects with type 2 diabetes and increased by SirT1. Diabetes, 58:23962401.

[99] Gao P, Xu TT, Lu J, Li L, Xu J, Hao DL, et al. (2014). Overexpression of SIRT1 in vascular smooth muscle cells attenuates angiotensin II-induced vascular remodeling and hypertension in mice. J Mol Med (Berl), 92:347-357.

[100] Gorenne I, Kumar S, Gray K, Figg N, Yu H, Mercer J, et al. (2013). Vascular smooth muscle cell sirtuin 1 protects against DNA damage and inhibits atherosclerosis. Circulation, 127:386-396.

[101] Hsu CP, Zhai P, Yamamoto T, Maejima Y, Matsushima $\mathrm{S}$, Hariharan $\mathrm{N}$, et al. (2010). Silent information regulator 1 protects the heart from ischemia/reperfusion. Circulation, 122:2170-2182.

[102] Luo XY, Qu SL, Tang ZH, Zhang Y, Liu MH, Peng J, et al. (2014). SIRT1 in cardiovascular aging. Clin Chim Acta, 437:106-114.

[103] Hashimoto-Komatsu A, Hirase T, Asaka M, Node K (2011). Angiotensin II induces microtubule reorganization mediated by a deacetylase SIRT2 in endothelial cells. Hypertens Res, 34:949-956.

[104] Sundaresan NR, Gupta M, Kim G, Rajamohan SB, Isbatan A, Gupta MP (2009). Sirt3 blocks the cardiac hypertrophic response by augmenting Foxo3adependent antioxidant defense mechanisms in mice. $\mathrm{J}$ Clin Invest, 119:2758-2771.

[105] Hafner AV, Dai J, Gomes AP, Xiao CY, Palmeira CM, Rosenzweig A, et al. (2010). Regulation of the mPTP by SIRT3-mediated deacetylation of CypD at lysine 166 suppresses age-related cardiac hypertrophy. Aging (Albany NY), 2:914-923.

[106] Jeong SM, Xiao C, Finley LW, Lahusen T, Souza AL, Pierce K, et al. (2013). SIRT4 has tumor-suppressive activity and regulates the cellular metabolic response to DNA damage by inhibiting mitochondrial glutamine metabolism. Cancer Cell, 23:450-463.

[107] Liu B, Che W, Zheng C, Liu W, Wen J, Fu H, et al. (2013). SIRT5: a safeguard against oxidative stressinduced apoptosis in cardiomyocytes. Cell Physiol Biochem, 32:1050-1059.

[108] Kim HS, Patel K, Muldoon-Jacobs K, Bisht KS, AykinBurns N, Pennington JD, et al. (2010). SIRT3 is a mitochondria-localized tumor suppressor required for maintenance of mitochondrial integrity and metabolism during stress. Cancer Cell, 17:41-52.

[109] Jia G, Su L, Singhal S, Liu X (2012). Emerging roles of SIRT6 on telomere maintenance, DNA repair, metabolism and mammalian aging. Mol Cell Biochem, $364: 345-350$
[110] Cencioni C, Spallotta F, Mai A, Martelli F, Farsetti A, Zeiher AM, et al. (2015). Sirtuin function in aging heart and vessels. J Mol Cell Cardiol, 83:55-61.

[111] Sundaresan NR, Pillai VB, Gupta MP (2011). Emerging roles of SIRT1 deacetylase in regulating cardiomyocyte survival and hypertrophy. J Mol Cell Cardiol, 51:614618.

[112] Sundaresan NR, Vasudevan P, Zhong L, Kim G, Samant S, Parekh V, et al. (2012). The sirtuin SIRT6 blocks IGF-Akt signaling and development of cardiac hypertrophy by targeting c-Jun. Nat Med, 18:16431650.

[113] Yang Y, Duan W, Li Y, Jin Z, Yan J, Yu S, et al. (2013). Novel role of silent information regulator 1 in myocardial ischemia. Circulation, 128:2232-2240.

[114] Grinker JA, Tucker K, Vokonas PS, Rush D (1995). Body habitus changes among adult males from the normative aging study: relations to aging, smoking history and alcohol intake. Obes Res, 3:435-446.

[115] Okabe K, Yaku K, Tobe K, Nakagawa T (2019). Implications of altered NAD metabolism in metabolic disorders. J Biomed Sci, 26:34.

[116] Herranz D, Munoz-Martin M, Canamero M, Mulero F, Martinez-Pastor B, Fernandez-Capetillo O, et al. (2010). Sirtl improves healthy ageing and protects from metabolic syndrome-associated cancer. Nat Commun, $1: 3$.

[117] Guo R, Liu W, Liu B, Zhang B, Li W, Xu Y (2015). SIRT1 suppresses cardiomyocyte apoptosis in diabetic cardiomyopathy: An insight into endoplasmic reticulum stress response mechanism. Int J Cardiol, 191:36-45.

[118] Ma L, Fu R, Duan Z, Lu J, Gao J, Tian L, et al. (2016). Sirtl is essential for resveratrol enhancement of hypoxia-induced autophagy in the type 2 diabetic nephropathy rat. Pathol Res Pract, 212:310-318.

[119] Kitada M, Ogura Y, Monno I, Koya D (2019). Sirtuins and Type 2 Diabetes: Role in Inflammation, Oxidative Stress, and Mitochondrial Function. Front Endocrinol (Lausanne), 10:187.

[120] Pfluger PT, Herranz D, Velasco-Miguel S, Serrano M, Tschop MH (2008). Sirtl protects against high-fat dietinduced metabolic damage. Proc Natl Acad Sci U S A, 105:9793-9798.

[121] Peng J, Zhou Y, Deng Z, Zhang H, Wu Y, Song T, et al. (2018). miR-221 negatively regulates inflammation and insulin sensitivity in white adipose tissue by repression of sirtuin-1 (SIRT1). J Cell Biochem, 119:6418-6428.

[122] Jiang W, Wang S, Xiao M, Lin Y, Zhou L, Lei Q, et al. (2011). Acetylation regulates gluconeogenesis by promoting PEPCK1 degradation via recruiting the UBR5 ubiquitin ligase. Mol Cell, 43:33-44.

[123] Gomes P, Fleming Outeiro T, Cavadas C (2015). Emerging Role of Sirtuin 2 in the Regulation of Mammalian Metabolism. Trends Pharmacol Sci, 36:756-768.

[124] Kincaid B, Bossy-Wetzel E (2013). Forever young: SIRT3 a shield against mitochondrial meltdown, aging, and neurodegeneration. Front Aging Neurosci, 5:48.

[125] Shimazu T, Hirschey MD, Hua L, Dittenhafer-Reed KE, Schwer B, Lombard DB, et al. (2010). SIRT3 
deacetylates mitochondrial 3-hydroxy-3methylglutaryl CoA synthase 2 and regulates ketone body production. Cell Metab, 12:654-661.

[126] Hirschey MD, Shimazu T, Goetzman E, Jing E, Schwer B, Lombard DB, et al. (2010). SIRT3 regulates mitochondrial fatty-acid oxidation by reversible enzyme deacetylation. Nature, 464:121-125.

[127] Schlicker C, Gertz M, Papatheodorou P, Kachholz B, Becker CF, Steegborn C (2008). Substrates and regulation mechanisms for the human mitochondrial sirtuins Sirt3 and Sirt5. J Mol Biol, 382:790-801.

[128] Finley LW, Carracedo A, Lee J, Souza A, Egia A, Zhang $\mathrm{J}$, et al. (2011). SIRT3 opposes reprogramming of cancer cell metabolism through HIFlalpha destabilization. Cancer Cell, 19:416-428.

[129] Caton PW, Richardson SJ, Kieswich J, Bugliani M, Holland ML, Marchetti P, et al. (2013). Sirtuin 3 regulates mouse pancreatic beta cell function and is suppressed in pancreatic islets isolated from human type 2 diabetic patients. Diabetologia, 56:1068-1077.

[130] Zhang HH, Ma XJ, Wu LN, Zhao YY, Zhang PY, Zhang YH, et al. (2016). Sirtuin-3 (SIRT3) protects pancreatic beta-cells from endoplasmic reticulum (ER) stressinduced apoptosis and dysfunction. Mol Cell Biochem, 420:95-106.

[131] Schwer B, Eckersdorff M, Li Y, Silva JC, Fermin D, Kurtev MV, et al. (2009). Calorie restriction alters mitochondrial protein acetylation. Aging Cell, 8:604606.

[132] Nasrin N, Wu X, Fortier E, Feng Y, Bare OC, Chen S, et al. (2010). SIRT4 regulates fatty acid oxidation and mitochondrial gene expression in liver and muscle cells. J Biol Chem, 285:31995-32002.

[133] Ahuja N, Schwer B, Carobbio S, Waltregny D, North BJ, Castronovo V, et al. (2007). Regulation of insulin secretion by SIRT4, a mitochondrial ADPribosyltransferase. J Biol Chem, 282:33583-33592.

[134] Laurent G, German NJ, Saha AK, de Boer VC, Davies M, Koves TR, et al. (2013). SIRT4 coordinates the balance between lipid synthesis and catabolism by repressing malonyl CoA decarboxylase. Mol Cell, 50:686-698.

[135] Jukarainen S, Heinonen S, Ramo JT, RinnankoskiTuikka R, Rappou E, Tummers M, et al. (2016). Obesity Is Associated With Low $\mathrm{NAD}(+) / \mathrm{SIRT}$ Pathway Expression in Adipose Tissue of BMI-Discordant Monozygotic Twins. J Clin Endocrinol Metab, 101:275-283.

[136] Sebastian C, Zwaans BM, Silberman DM, Gymrek M, Goren A, Zhong L, et al. (2012). The histone deacetylase SIRT6 is a tumor suppressor that controls cancer metabolism. Cell, 151:1185-1199.

[137] Kanfi Y, Peshti V, Gil R, Naiman S, Nahum L, Levin E, et al. (2010). SIRT6 protects against pathological damage caused by diet-induced obesity. Aging Cell, 9:162-173.

[138] Song MY, Wang J, Ka SO, Bae EJ, Park BH (2016). Insulin secretion impairment in Sirt6 knockout pancreatic beta cells is mediated by suppression of the FoxO1-Pdx1-Glut2 pathway. Sci Rep, 6:30321.
[139] Yuan H, Su L, Chen WY (2013). The emerging and diverse roles of sirtuins in cancer: a clinical perspective. Onco Targets Ther, 6:1399-1416.

[140] Chalkiadaki A, Guarente L (2015). The multifaceted functions of sirtuins in cancer. Nat Rev Cancer, 15:608624.

[141] Taylor DM, Maxwell MM, Luthi-Carter R, Kazantsev AG (2008). Biological and potential therapeutic roles of sirtuin deacetylases. Cell Mol Life Sci, 65:4000-4018.

[142] Jin X, Wei Y, Xu F, Zhao M, Dai K, Shen R, et al. (2018). SIRT1 promotes formation of breast cancer through modulating Akt activity. J Cancer, 9:2012-2023.

[143] Jang KY, Noh SJ, Lehwald N, Tao GZ, Bellovin DI, Park HS, et al. (2012). SIRT1 and c-Myc promote liver tumor cell survival and predict poor survival of human hepatocellular carcinomas. PLoS One, 7:e45119.

[144] Chen X, Sun K, Jiao S, Cai N, Zhao X, Zou H, et al. (2014). High levels of SIRT1 expression enhance tumorigenesis and associate with a poor prognosis of colorectal carcinoma patients. Sci Rep, 4:7481.

[145] Li L, Osdal T, Ho Y, Chun S, McDonald T, Agarwal P, et al. (2014). SIRT1 activation by a c-MYC oncogenic network promotes the maintenance and drug resistance of human FLT3-ITD acute myeloid leukemia stem cells. Cell Stem Cell, 15:431-446.

[146] Kang YY, Sun FL, Zhang Y, Wang Z (2018). SIRT1 acts as a potential tumor suppressor in oral squamous cell carcinoma. J Chin Med Assoc, 81:416-422.

[147] Firestein R, Blander G, Michan S, Oberdoerffer P, Ogino S, Campbell J, et al. (2008). The SIRT1 deacetylase suppresses intestinal tumorigenesis and colon cancer growth. PLoS One, 3:e2020.

[148] Wang RH, Sengupta K, Li C, Kim HS, Cao L, Xiao C, et al. (2008). Impaired DNA damage response, genome instability, and tumorigenesis in SIRT1 mutant mice. Cancer Cell, 14:312-323.

[149] Park SH, Zhu Y, Ozden O, Kim HS, Jiang H, Deng CX, et al. (2012). SIRT2 is a tumor suppressor that connects aging, acetylome, cell cycle signaling, and carcinogenesis. Transl Cancer Res, 1:15-21.

[150] McGlynn LM, Zino S, MacDonald AI, Curle J, Reilly JE, Mohammed ZM, et al. (2014). SIRT2: tumour suppressor or tumour promoter in operable breast cancer? Eur J Cancer, 50:290-301.

[151] Allison SJ, Milner J (2007). SIRT3 is pro-apoptotic and participates in distinct basal apoptotic pathways. Cell Cycle, 6:2669-2677.

[152] Alhazzazi TY, Kamarajan P, Joo N, Huang JY, Verdin E, D'Silva NJ, et al. (2011). Sirtuin-3 (SIRT3), a novel potential therapeutic target for oral cancer. Cancer, 117:1670-1678.

[153] Aury-Landas J, Bougeard G, Castel H, HernandezVargas H, Drouet A, Latouche JB, et al. (2013). Germline copy number variation of genes involved in chromatin remodelling in families suggestive of $\mathrm{Li}$ Fraumeni syndrome with brain tumours. Eur J Hum Genet, 21:1369-1376.

[154] Garber ME, Troyanskaya OG, Schluens K, Petersen S, Thaesler Z, Pacyna-Gengelbach M, et al. (2001). Diversity of gene expression in adenocarcinoma of the 
lung. Proc Natl Acad Sci U S A, 98:13784-13789.

[155] Wang Q, Wen YG, Li DP, Xia J, Zhou CZ, Yan DW, et al. (2012). Upregulated INHBA expression is associated with poor survival in gastric cancer. Med Oncol, 29:77-83.

[156] Choi YL, Tsukasaki K, O'Neill MC, Yamada Y, Onimaru Y, Matsumoto K, et al. (2007). A genomic analysis of adult T-cell leukemia. Oncogene, 26:12451255.

[157] Director's Challenge Consortium for the Molecular Classification of Lung A, Shedden K, Taylor JM, Enkemann SA, Tsao MS, Yeatman TJ, et al. (2008). Gene expression-based survival prediction in lung adenocarcinoma: a multi-site, blinded validation study. Nat Med, 14:822-827.

[158] Jeong SM, Hwang S, Seong RH (2016). SIRT4 regulates cancer cell survival and growth after stress. Biochem Biophys Res Commun, 470:251-256.

[159] Lu W, Zuo Y, Feng Y, Zhang M (2014). SIRT5 facilitates cancer cell growth and drug resistance in non-small cell lung cancer. Tumour Biol, 35:1069910705.

[160] Kumar S, Lombard DB (2015). Mitochondrial sirtuins and their relationships with metabolic disease and cancer. Antioxid Redox Signal, 22:1060-1077.

[161] Lai CC, Lin PM, Lin SF, Hsu CH, Lin HC, Hu ML, et al. (2013). Altered expression of SIRT gene family in head and neck squamous cell carcinoma. Tumour Biol, 34:1847-1854.

[162] Bartosch C, Monteiro-Reis S, Almeida-Rios D, Vieira $\mathrm{R}$, Castro A, Moutinho M, et al. (2016). Assessing sirtuin expression in endometrial carcinoma and nonneoplastic endometrium. Oncotarget, 7:1144-1154.

[163] Negrini S, Gorgoulis VG, Halazonetis TD (2010). Genomic instability--an evolving hallmark of cancer. Nat Rev Mol Cell Biol, 11:220-228.

[164] Tennen RI, Chua KF (2011). Chromatin regulation and genome maintenance by mammalian SIRT6. Trends Biochem Sci, 36:39-46.

[165] Van Meter M, Mao Z, Gorbunova V, Seluanov A (2011). SIRT6 overexpression induces massive apoptosis in cancer cells but not in normal cells. Cell Cycle, 10:3153-3158.

[166] Zwaans BM, Lombard DB (2014). Interplay between sirtuins, MYC and hypoxia-inducible factor in cancerassociated metabolic reprogramming. Dis Model Mech, 7:1023-1032.

[167] Kim EJ, Juhnn YS (2015). Cyclic AMP signaling reduces sirtuin 6 expression in non-small cell lung cancer cells by promoting ubiquitin-proteasomal degradation via inhibition of the Raf-MEK-ERK (Raf/mitogen-activated extracellular signal-regulated kinase/extracellular signal-regulated kinase) pathway. J Biol Chem, 290:9604-9613.

[168] Bauer I, Grozio A, Lasiglie D, Basile G, Sturla L, Magnone M, et al. (2012). The NAD+-dependent histone deacetylase SIRT6 promotes cytokine production and migration in pancreatic cancer cells by regulating Ca2+ responses. J Biol Chem, 287:4092440937.
[169] Liu Y, Xie QR, Wang B, Shao J, Zhang T, Liu T, et al. (2013). Inhibition of SIRT6 in prostate cancer reduces cell viability and increases sensitivity to chemotherapeutics. Protein Cell, 4:702-710.

[170] Khongkow M, Olmos Y, Gong C, Gomes AR, Monteiro LJ, Yague E, et al. (2013). SIRT6 modulates paclitaxel and epirubicin resistance and survival in breast cancer. Carcinogenesis, 34:1476-1486.

[171] Ming M, Han W, Zhao B, Sundaresan NR, Deng CX, Gupta MP, et al. (2014). SIRT6 promotes COX-2 expression and acts as an oncogene in skin cancer. Cancer Res, 74:5925-5933.

[172] Kim JK, Noh JH, Jung KH, Eun JW, Bae HJ, Kim MG, et al. (2013). Sirtuin7 oncogenic potential in human hepatocellular carcinoma and its regulation by the tumor suppressors MiR-125a-5p and MiR-125b. Hepatology, 57:1055-1067.

[173] Ashraf N, Zino S, Macintyre A, Kingsmore D, Payne AP, George WD, et al. (2006). Altered sirtuin expression is associated with node-positive breast cancer. Br J Cancer, 95:1056-1061.

[174] De Nigris F, Cerutti J, Morelli C, Califano D, Chiariotti L, Viglietto G, et al. (2002). Isolation of a SIR-like gene, SIR-T8, that is overexpressed in thyroid carcinoma cell lines and tissues. Br J Cancer, 87:1479.

[175] Masoro EJ (2005). Overview of caloric restriction and ageing. Mech Ageing Dev, 126:913-922.

[176] Ingram DK, Roth GS (2015). Calorie restriction mimetics: can you have your cake and eat it, too? Ageing Res Rev, 20:46-62.

[177] Colman RJ, Anderson RM, Johnson SC, Kastman EK, Kosmatka KJ, Beasley TM, et al. (2009). Caloric restriction delays disease onset and mortality in rhesus monkeys. Science, 325:201-204.

[178] Satoh A, Brace CS, Rensing N, Cliften P, Wozniak DF, Herzog ED, et al. (2013). Sirt1 extends life span and delays aging in mice through the regulation of $\mathrm{Nk} 2$ homeobox 1 in the DMH and LH. Cell Metab, 18:416430.

[179] Howitz KT, Bitterman KJ, Cohen HY, Lamming DW, Lavu S, Wood JG, et al. (2003). Small molecule activators of sirtuins extend Saccharomyces cerevisiae lifespan. Nature, 425:191-196.

[180] Barger JL, Kayo T, Pugh TD, Prolla TA, Weindruch R (2008). Short-term consumption of a resveratrolcontaining nutraceutical mixture mimics gene expression of long-term caloric restriction in mouse heart. Exp Gerontol, 43:859-866.

[181] Pearson KJ, Baur JA, Lewis KN, Peshkin L, Price NL, Labinskyy N, et al. (2008). Resveratrol delays agerelated deterioration and mimics transcriptional aspects of dietary restriction without extending life span. Cell Metab, 8:157-168.

[182] Harper CE, Patel BB, Wang J, Arabshahi A, Eltoum IA, Lamartiniere CA (2007). Resveratrol suppresses prostate cancer progression in transgenic mice. Carcinogenesis, 28:1946-1953.

[183] Li T, Fan GX, Wang W, Li T, Yuan YK (2007). Resveratrol induces apoptosis, influences IL-6 and exerts immunomodulatory effect on mouse 
lymphocytic leukemia both in vitro and in vivo. Int Immunopharmacol, 7:1221-1231.

[184] Whitsett T, Carpenter M, Lamartiniere CA (2006). Resveratrol, but not EGCG, in the diet suppresses DMBA-induced mammary cancer in rats. J Carcinog, $5: 15$.

[185] Milne JC, Lambert PD, Schenk S, Carney DP, Smith JJ, Gagne DJ, et al. (2007). Small molecule activators of SIRT1 as therapeutics for the treatment of type 2 diabetes. Nature, 450:712-716.

[186] Ota H, Eto M, Kano MR, Ogawa S, Iijima K, Akishita M, et al. (2008). Cilostazol inhibits oxidative stressinduced premature senescence via upregulation of Sirt1 in human endothelial cells. Arterioscler Thromb Vasc Biol, 28:1634-1639.

[187] Jamal J, Mustafa MR, Wong PF (2014). Paeonol protects against premature senescence in endothelial cells by modulating Sirtuin 1 pathway. J Ethnopharmacol, 154:428-436.

[188] Ota H, Eto M, Kano MR, Kahyo T, Setou M, Ogawa S, et al. (2010). Induction of endothelial nitric oxide synthase, SIRT1, and catalase by statins inhibits endothelial senescence through the Akt pathway. Arterioscler Thromb Vasc Biol, 30:2205-2211.

[189] Suo R, Zhao ZZ, Tang ZH, Ren Z, Liu X, Liu LS, et al. (2013). Hydrogen sulfide prevents $\mathrm{H}(2) \mathrm{O}(2)$-induced senescence in human umbilical vein endothelial cells through SIRT1 activation. Mol Med Rep, 7:1865-1870.

[190] Zheng M, Qiao W, Cui J, Liu L, Liu H, Wang Z, et al. (2014). Hydrogen sulfide delays nicotinamide-induced premature senescence via upregulation of SIRT1 in human umbilical vein endothelial cells. Mol Cell Biochem, 393:59-67.

[191] Lee YA, Cho EJ, Yokozawa T (2008). Protective effect of persimmon (Diospyros kaki) peel proanthocyanidin against oxidative damage under $\mathrm{H} 2 \mathrm{O} 2$-induced cellular senescence. Biol Pharm Bull, 31:1265-1269.

[192] Dai H, Kustigian L, Carney D, Case A, Considine T, Hubbard BP, et al. (2010). SIRT1 activation by small molecules: kinetic and biophysical evidence for direct interaction of enzyme and activator. J Biol Chem, 285:32695-32703.

[193] Hubbard BP, Sinclair DA (2014). Small molecule SIRT1 activators for the treatment of aging and agerelated diseases. Trends Pharmacol Sci, 35:146-154.

[194] Jayasena T, Poljak A, Smythe G, Braidy N, Munch G, Sachdev P (2013). The role of polyphenols in the modulation of sirtuins and other pathways involved in Alzheimer's disease. Ageing Res Rev, 12:867-883.

[195] Wang G, Han T, Nijhawan D, Theodoropoulos P, Naidoo J, Yadavalli S, et al. (2014). P7C3 neuroprotective chemicals function by activating the rate-limiting enzyme in NAD salvage. Cell, 158:13241334.

[196] Escande C, Nin V, Price NL, Capellini V, Gomes AP, Barbosa MT, et al. (2013). Flavonoid apigenin is an inhibitor of the NAD+ ase CD38: implications for cellular NAD + metabolism, protein acetylation, and treatment of metabolic syndrome. Diabetes, 62:10841093.
[197] Braidy N, Poljak A, Grant R, Jayasena T, Mansour H, Chan-Ling $\mathrm{T}$, et al. (2014). Mapping $\mathrm{NAD}(+)$ metabolism in the brain of ageing Wistar rats: potential targets for influencing brain senescence. Biogerontology, 15:177-198.

[198] Anderson RM, Bitterman KJ, Wood JG, Medvedik O, Sinclair DA (2003). Nicotinamide and PNC1 govern lifespan extension by calorie restriction in Saccharomyces cerevisiae. Nature, 423:181-185.

[199] Anderson RM, Bitterman KJ, Wood JG, Medvedik O, Cohen H, Lin SS, et al. (2002). Manipulation of a nuclear NAD + salvage pathway delays aging without altering steady-state NAD + levels. J Biol Chem, 277:18881-18890.

[200] Gomes AP, Price NL, Ling AJ, Moslehi JJ, Montgomery MK, Rajman L, et al. (2013). Declining $\mathrm{NAD}(+)$ induces a pseudohypoxic state disrupting nuclear-mitochondrial communication during aging. Cell, 155:1624-1638.

[201] Chang HC, Guarente L (2013). SIRT1 mediates central circadian control in the SCN by a mechanism that decays with aging. Cell, 153:1448-1460.

[202] Gong B, Pan Y, Vempati P, Zhao W, Knable L, Ho L, et al. (2013). Nicotinamide riboside restores cognition through an upregulation of proliferator-activated receptor-gamma coactivator 1alpha regulated betasecretase 1 degradation and mitochondrial gene expression in Alzheimer's mouse models. Neurobiol Aging, 34:1581-1588.

[203] Zhang H, Ryu D, Wu Y, Gariani K, Wang X, Luan P, et al. (2016). $\mathrm{NAD}(+)$ repletion improves mitochondrial and stem cell function and enhances life span in mice. Science, 352:1436-1443.

[204] Haffner CD, Becherer JD, Boros EE, Cadilla R, Carpenter T, Cowan D, et al. (2015). Discovery, Synthesis, and Biological Evaluation of Thiazoloquin(az)olin(on)es as Potent CD38 Inhibitors. J Med Chem, 58:3548-3571.

[205] Jiang Y, Liu J, Chen D, Yan L, Zheng W (2017). Sirtuin Inhibition: Strategies, Inhibitors, and Therapeutic Potential. Trends Pharmacol Sci, 38:459-472.

[206] Rumpf T, Gerhardt S, Einsle O, Jung M (2015). Seeding for sirtuins: microseed matrix seeding to obtain crystals of human Sirt3 and Sirt2 suitable for soaking. Acta Crystallogr F Struct Biol Commun, 71:1498-1510.

[207] Cui H, Kamal Z, Ai T, Xu Y, More SS, Wilson DJ, et al. (2014). Discovery of potent and selective sirtuin 2 (SIRT2) inhibitors using a fragment-based approach. J Med Chem, 57:8340-8357.

[208] Chopra V, Quinti L, Kim J, Vollor L, Narayanan KL, Edgerly C, et al. (2012). The sirtuin 2 inhibitor AK-7 is neuroprotective in Huntington's disease mouse models. Cell Rep, 2:1492-1497.

[209] Li L, Wang L, Li L, Wang Z, Ho Y, McDonald T, et al. (2012). Activation of p53 by SIRT1 inhibition enhances elimination of CML leukemia stem cells in combination with imatinib. Cancer Cell, 21:266-281.

[210] Rotili D, Tarantino D, Carafa V, Paolini C, Schemies J, Jung M, et al. (2012). Benzodeazaoxaflavins as sirtuin inhibitors with antiproliferative properties in cancer 
stem cells. J Med Chem, 55:8193-8197.

[211] Schuetz A, Min J, Antoshenko T, Wang CL, AllaliHassani A, Dong A, et al. (2007). Structural basis of inhibition of the human NAD+-dependent deacetylase
SIRT5 by suramin. Structure, 15:377-389.

[212] Ferrari CK (2004). Functional foods, herbs and nutraceuticals: towards biochemical mechanisms of healthy aging. Biogerontology, 5:275-289. 